\title{
WestVirginiaUniversity
}

THE RESEARCH REPOSITORY @ WVU

Graduate Theses, Dissertations, and Problem Reports

2012

\section{Combining Language---A Study of English-Chinese Bilingual Typography}

\author{
Yan Zhao \\ West Virginia University
}

Follow this and additional works at: https://researchrepository.wvu.edu/etd

\section{Recommended Citation}

Zhao, Yan, "Combining Language---A Study of English-Chinese Bilingual Typography" (2012). Graduate Theses, Dissertations, and Problem Reports. 3319.

https://researchrepository.wvu.edu/etd/3319

This Thesis is protected by copyright and/or related rights. It has been brought to you by the The Research Repository @ WVU with permission from the rights-holder(s). You are free to use this Thesis in any way that is permitted by the copyright and related rights legislation that applies to your use. For other uses you must obtain permission from the rights-holder(s) directly, unless additional rights are indicated by a Creative Commons license in the record and/ or on the work itself. This Thesis has been accepted for inclusion in WVU Graduate Theses, Dissertations, and Problem Reports collection by an authorized administrator of The Research Repository @ WVU. For more information, please contact researchrepository@mail.wvu.edu. 


\title{
Combining Language- A Study of English-Chinese Bilingual Typography
}

\author{
Yan Zhao \\ Thesis submitted to the \\ College of Creative Arts \\ West Virginia University \\ in partial fulfillment of the requirements \\ for the degree of \\ Master of Fine Arts \\ in \\ Visual Communication/Graphic Design
}
Eve Faulkes, Chair
Joseph Galbreath
Gerald Habarth
Joyce Ice
School of Art and Design
Morgantown, West Virginia
2012

Key Words: English, Chinese, Bilingual, Typography, Print Publication

Copyright 2012 Yan Zhao 


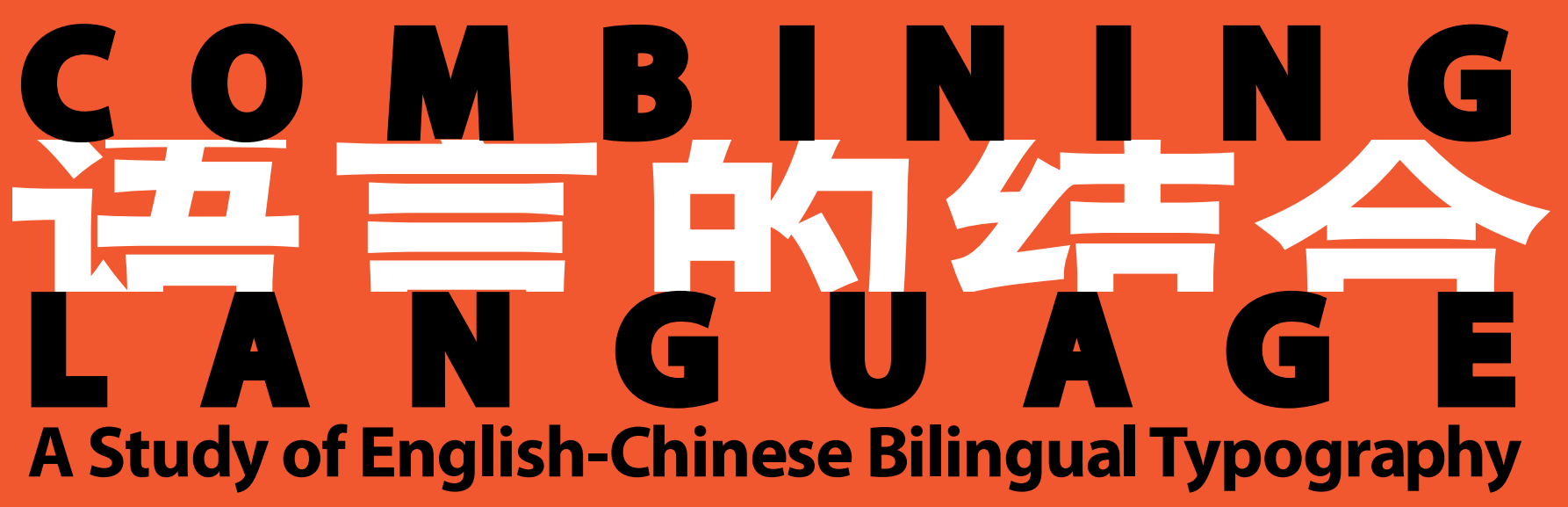
中 英文双语字体设计研究 MFA Candidate艺术硕士候选人: Yan Zhao趙岩, 2012 


\section{ABSTRACT摘要}

\section{Combining Language-}

A Study of English-Chinese

Bilingual Typography

Yan Zhao

Due to increased globalization, English and Chinese typographies have been used together and have come to characterize many publications and educational materials, commonly appearing in airports, museums and city shopping districts. This MFA thesis is inspired by this realization and is geared toward enhancing new methods for balancing English-Chinese bilingual typography in print.

Key Words: English, Chinese, Bilingual, Typography, Print Publication 


\section{TABLE OF CONTENTS目录}

Acknowledgement

Introduction

Current Research

Comparison of English and Chinese Typographies $\quad 12$

Space, kerning, and punctuation

Ascenders, descenders and case

Sizes and leading

Reading order

Justification

Problems in English-Chinese Bilingual Typography

Size and leading

Density

Readability

Paragraph length

Reading order

Flexibility

Balancing the Two Typographies

Paragraph length treatment

Paragraph weight treatment

Choice of fonts

Quantity of types

Interesting Purposes

Creating hierarchy

Type as image

Sharing mutual parts

Embedding types in each other

Transparency

Others

Conclusion and Demonstration

List of Works Included in the Thesis Exhibit

References 


\section{ACKNOWLEDGEMENTS鸣谢}

I would like to thank my committee, Eve Faulkes, Gerald Habarth, Joseph Galbreath, Joyce Ice, and former professor Chris Barr for their help and continuing support of the last few years.

Eve, thank you for your patience and hard work. You have set a great example for me as a designer and a person.

Many thanks to my family, friends and graduate peers. Your kindness and support have sustained me during the past few years. A special thank you to my mentor and friend Erin McCanlies and her family who are always there for me. 


\section{简分 \\ INTRODUCTION}

Due to globalization, letters and characters from different origins, especially those of English and Chinese origin, have been converging with increasing frequency and restructuring the foundation of written communication. English and Chinese come together and characterize the appearance of many print publications, institutions, universities, trade fair sites, airports, educational materials, Internet portals and city districts. However the basic principles of written communication affected by the coexistence of the two languages haven't been explored in depth. ${ }^{1}$

In this research, English-Chinese bilingual "coexistence" is interpreted as:

1. When two languages appear together on a single substrate in an attempt to create the impression that they exist parallel to each other;

2. "Code-mixing"-when one language is embedded in the other. ${ }^{2}$

1 Keith Tam mentioned that he intended to "provide a starting point for future discourse and research on bilingual typography" in his article Typographic Bilingualism: A Framework for the Coexistence of Chinese \& English Texts in 2007. There are other research studies that have been done since then, but systematic research has not been done.

2 Keith Tam, Typographic bilingualism: A Framework for the Coexistence of Chinese \& English Texts, 2007, http://luc. devroye.org/fonts-39913.html. 
Even though English-Chinese bilingual typography in web layout design shares many common rules with those in print publication, there are still many differences in terms of readability and ways to view the designs. This thesis mainly focuses on print publication including page layout, signage, posters, and logo design.

The objectives of this thesis are:

- Study the formal distinction between existing Chinese and English typefaces displayed by single aspects, categories, and schematic representation.

- Study the problems existing in English-Chinese bilingual typography design.

- Explore principles for a peaceful coexistence of characters.

- Explore new methods of combining Chinese-English bilingual typography for print publication.

The research aims to preserve the respective distinctiveness of both typographic cultures, and make contributions towards solving the problems of an increasingly globalized design process. Hopefully designers can benefit from this research in their bilingual design projects. 


\title{
研究现状及灵感来源 \\ CURRENT RESEARCH \& INSPIRATION
}

\author{
Research about English-Chinese bilingual design has drawn \\ designers' attention in recent years. One of the largest \\ ongoing projects is "Multilingual Typography" established by \\ Designzcontext Research Institute, Zurich University, \\ Switzerland in 2010. "Multilingual Typography" is an \\ interdisciplinary project situated at the interface between \\ visual communication, typographic design, signage, and the \\ designing of public space. The research mainly focuses on the \\ coexistence of Latin and Chinese types including German, \\ English and Chinese. They have conducted five two-week
}

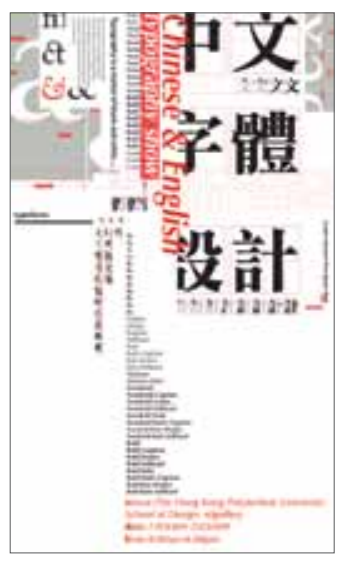

Chinese \& English

Typography Show Poster,

2009, Multilingual typography and School of Design, Hong Kong Polytechnic University

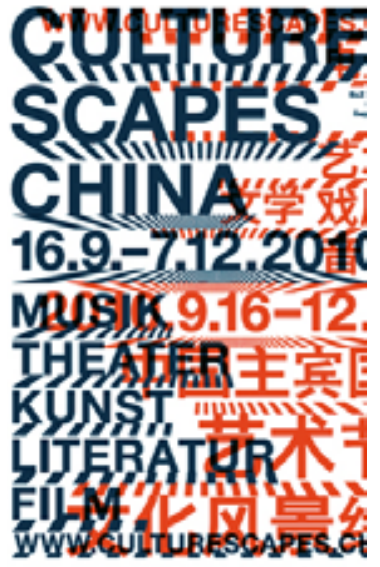

Culturescapes

Festivalzeitung,

"Culturescapes" festival maga-

zine, 2010,

Multilingual typography

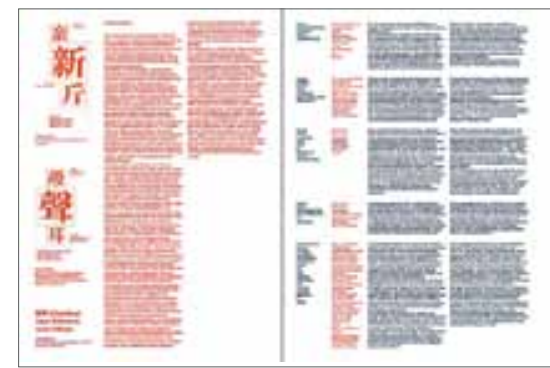

Culturescapes

Festivalzeitung,

"Culturescapes" festival

magazine, 2010,

Multilingual typography 


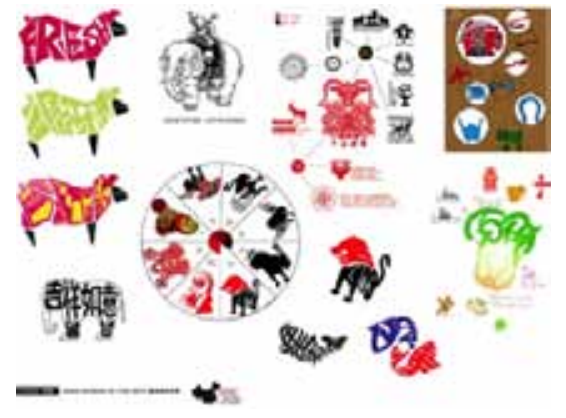

Workshop at Luxun Academy of Arts (鲁迅美术学院), Department of Visual Communication in Shenyang, 2010 Multilingual typography

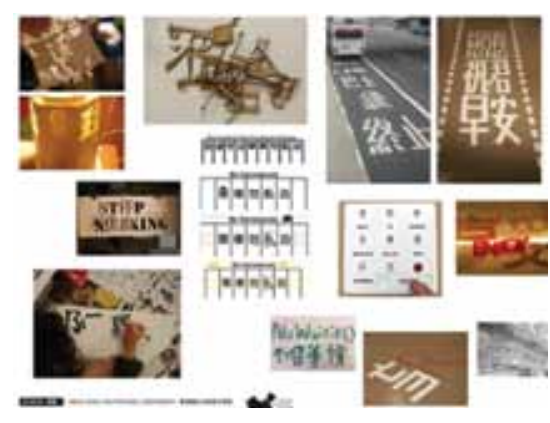

Workshop at Hong Kong Polytechnic University, School of Design, in Hong Kong, 2009 Multilingual typography workshops in conjunction with five Chinese universities, in order to develop and test basic design practices. The main questions they wanted to answer are: which specific scripts, symbols, and pictorial languages characterize the two cultural contexts? Which historical, cultural, and social issues are associated with them? Exhibitions were followed by the workshops. The project transferred the workshop and exhibitions experiences to date into various courses and lectures. A publication dedicated to presenting the development of design methods and models, as well as educational tools and user manuals for the visualization and communication of multilingualism has been planned for publication in the near future. ${ }^{1}$

"Multilingual Typography" has done a great job on developing the topic, drawing designer's attention, and also building a framework of the multilingual typography research. But as an ongoing project, the results have not fully come out yet. The past research shows a little lack of systematic conduct due to too many institutions, people and schools involved.

1 Multilingual Typography, http://multilingual-typography.zhdk.ch 

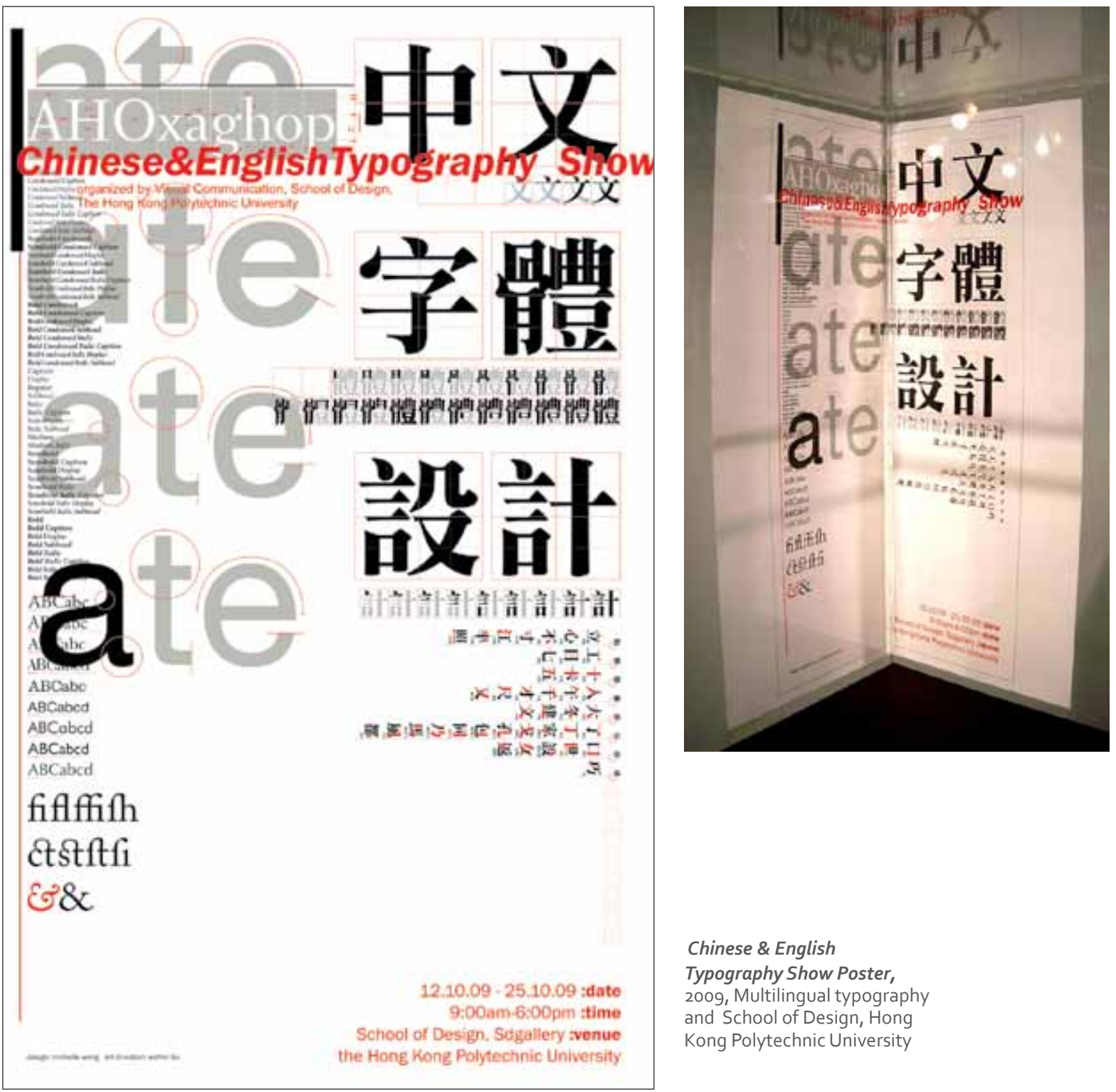

Chinese \& English

Typography Show Poster,

2009, Multilingual typography

and School of Design, Hong

Kong Polytechnic University 


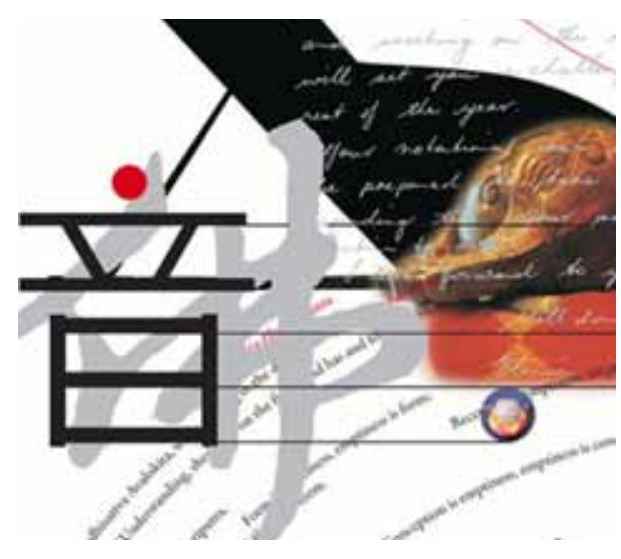

Graphic Design as Art, Detail, Joseph Ku

There are also some individual designers who have been experimenting with Chinese-English bilingual typography such as bilingual typeface designer Winnie Tan (Singapore), Yiming( 意冥)(Hong kong), and Joseph Ku (Switzerland). One of the most noticeable designers in this field is Keith Tam from Hong Kong. His ideas were published in Typographic Bilingualism: A framework for the Coexistence of Chinese \& English Texts at ATYPI Conference in UK, 2007. He attempts to create a framework for describing and analyzing the typographic design of Chinese-English bilingual texts through an investigation on the influence of content, visual attributes and spatial organization on perception and comprehension. He did a case study on Hong Kong, where Chinese and English are both official languages and frequently coexist. The designer thinks that size relationships, visual attributes, relative positioning, articulation, and order in sequence, use of color, etc. are important decisions that a typographic designer has

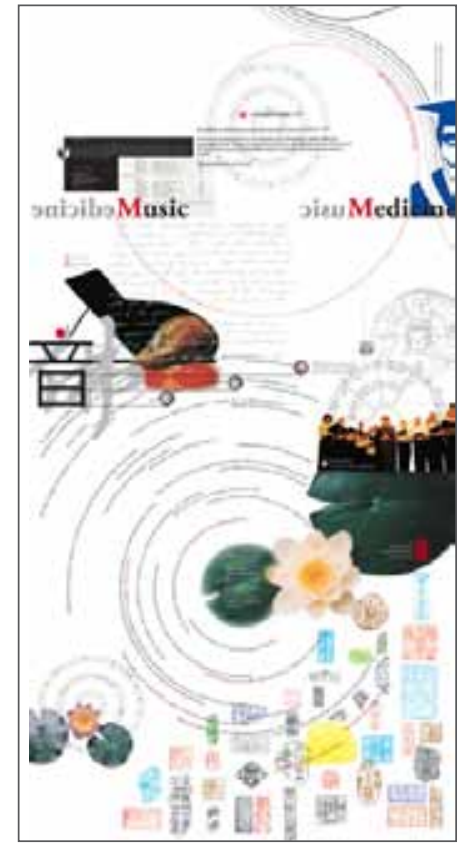

Graphic Design as Art, $50 \mathrm{~cm} \times 100 \mathrm{~cm}$, digital print on canvas, 2010, Joseph Ku

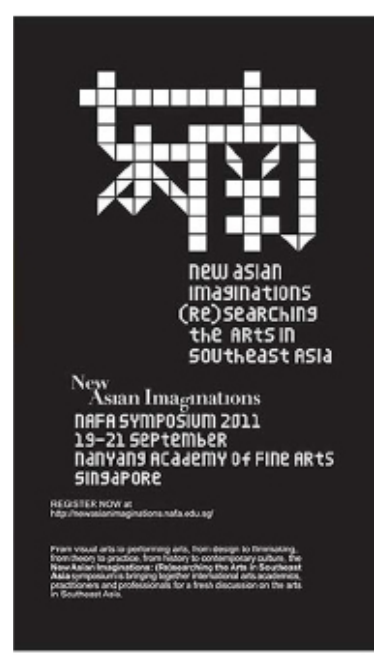

Bilingual Typeface "Simple" in Use, Winnie Tan, 2011 


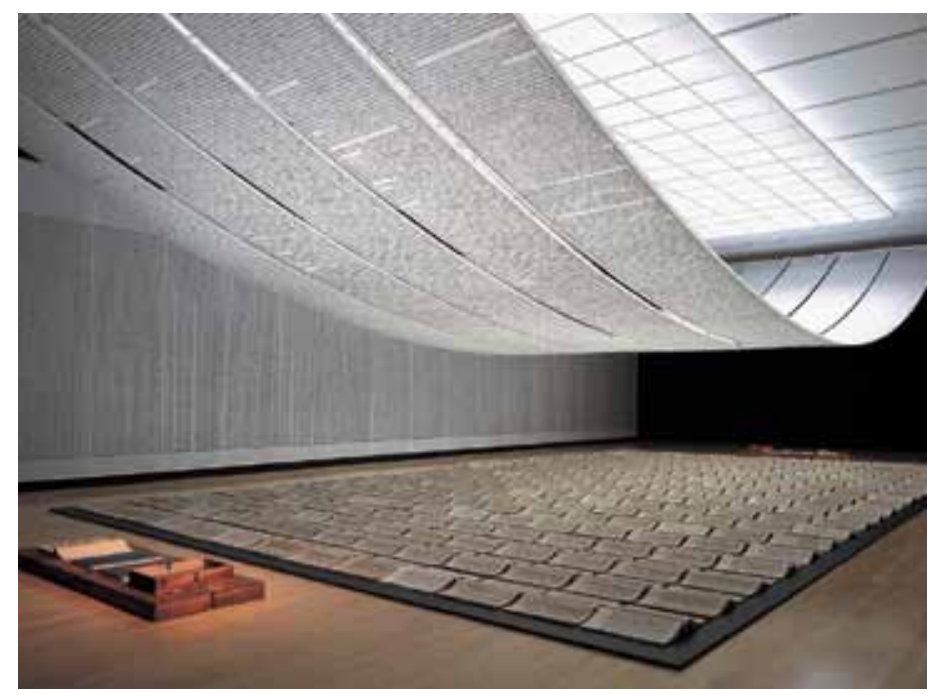

to make when designing with two languages. He also pointed out that the context of use, intended audience, respect for the cultural traditions and customs, language conventions, and the anticipated perception of status, authority and formality will dictate how these bilingual design decisions are made. ${ }^{2}$

Keith Tam has done a insightful job on the study of coexistence of Chinese-English typography in Hong Kong, and also pointed out important aspects that bilingual designer should pay attention to. But as he mentioned, the detail rules of bilingual typography still need to be defined.

Some artists also relate their works to typography in terms of enhancing communication among cultures. Chinese contemporary artist Xu Bing (born 1955) is one of the most influential ones. Using types as a media, Xu intends to break the cultural difference and inspire people to communicate in new ways. Three of his most popular works are: A Book from the Sky

2 Keith Tam, Typographic bilingualism: A Framework for the Coexistence of Chinese \& English Texts, 2007.
A Book from the Sky, Xu Bing, 1988

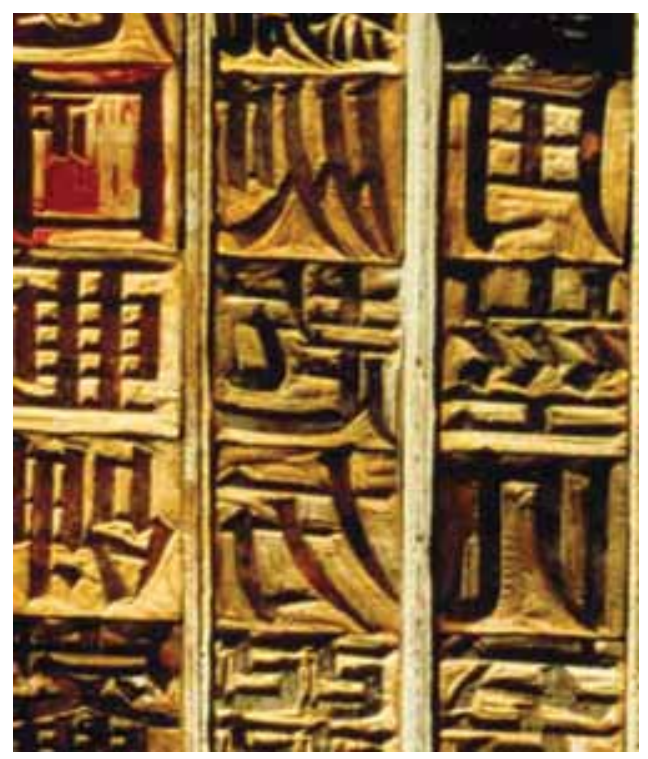

Wood Block, A Book from the Sky, Xu Bing, 1988 


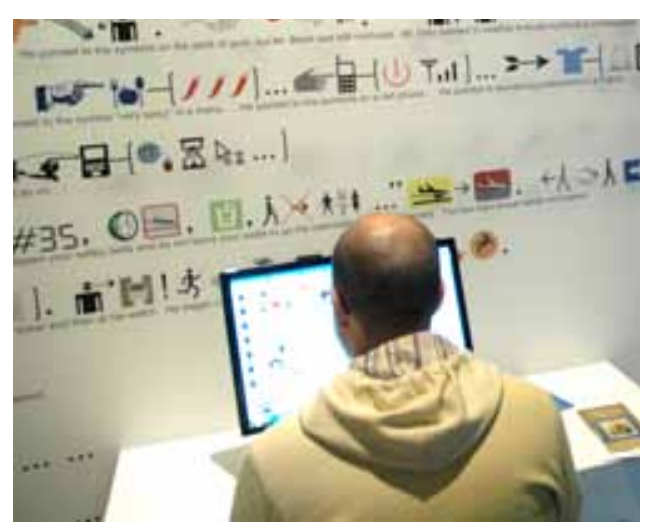

A Book from the Ground, Xu Bing, 2003

(1987-1991), A Book from the Ground (2003-ongoing) and Introduction of New Chinese Calligraphy (1994-1996). A Book from the Sky is an installation artwork consisting of a set of books, panels and scrolls on which were printed thousands of characters resembling real Chinese characters, all devoid of semantic content. Xu spent years hand carving the typesetting blocks used to make the prints according to traditional Chinese block printing methods. Each block was embossed with a unique but meaningless symbol and then used to make the prints for the exhibit. The artist believes that if a work can be explained with words, then there can be no reason for it to exist. In front of this work, people with different cultural backgrounds stand equal, because nobody ever can read it.

A Book from the Ground, opposite to A Book from the Sky, creates a way for everybody with different cultural backgrounds to read the contexts. The piece uses pictographs so that speakers of any language can communicate. It breaks down differences across the globe and inspires people to think about the modern era and its universal communication.

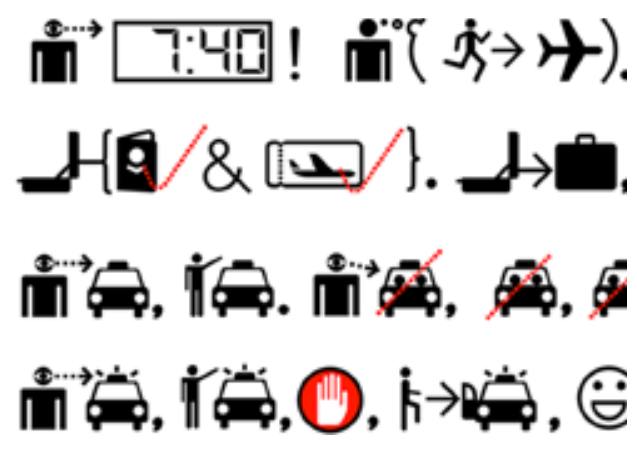

A Book from the Ground, Xu Bing, 2003 

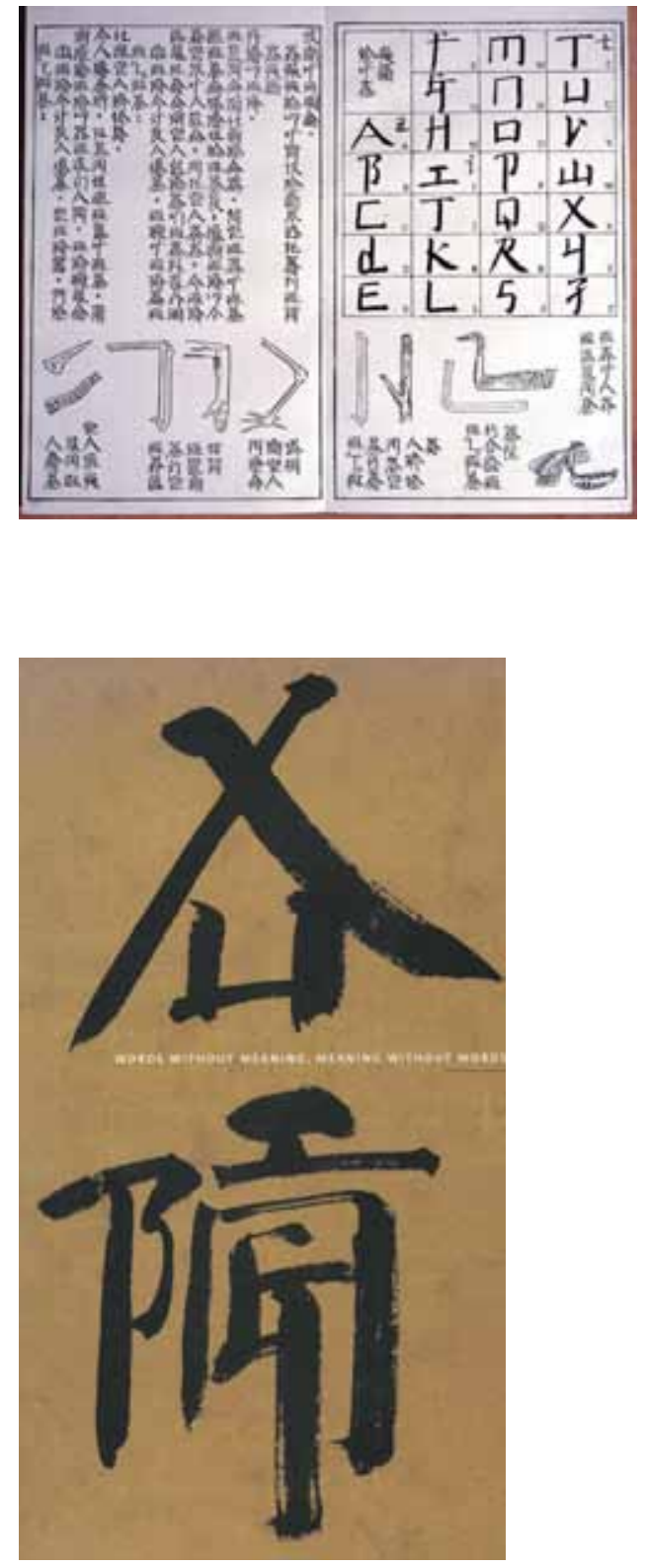

Xu Bing, Xu Bing
Introduction of New Chinese

Calligraphy, Xu Bing, 1996

Introduction of New Chinese Typography (1994-1996) has a more direct idea to bring people from different cultural backgrounds together. In this work Xu writes in English using Chinese brush strokes. At first glance, it looks Chinese and Chinese readers expect to be able to read it, but can't. English readers don't bother trying, and it is only when the trick is revealed do they realize the text is completely illegible. Xu Bing has transcribed common poetry, political passages, and even nursery rhymes into New English Calligraphy. In addition, Xu Bing also conducts New English Calligraphy Classes, where participants sit in a traditional Chinese classroom style practicing the use of the ink brush to create Chinese characters, or in this case, English characters, while a television instructs them. His work reminds people that we tend to block out other cultures before trying to understand them, simply because of the first impression. Also sometimes cultural forms act as a barrier rather than a bridge.

Xu Bing's art provides two very important ideas: difference in typography forms could be barriers for communication; and 


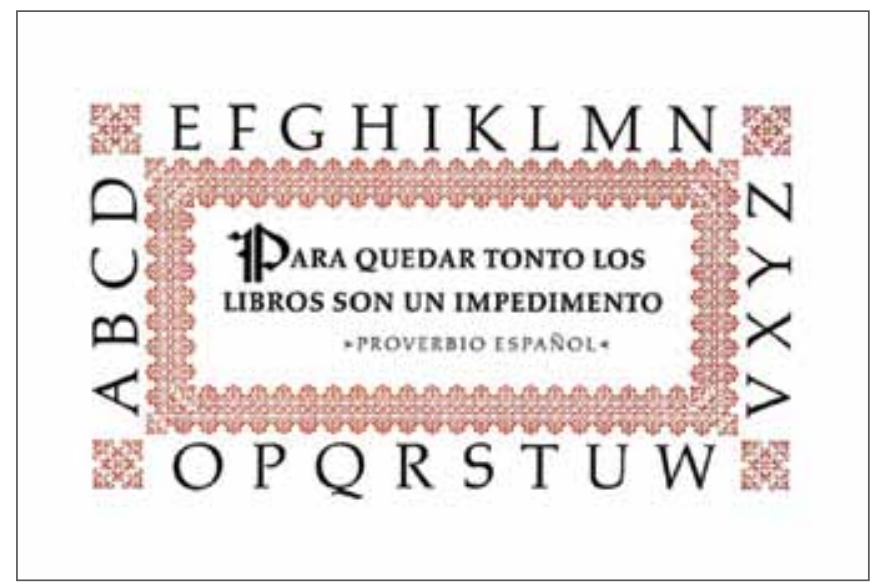

Manuale Typographicum, Hermann Zapf

to break the barriers, typography helps different cultures communicate. Use of bilingual typography in other languages such as Arabic and English also provides many effective solutions for bilingual typography problems, and they are also great inspiration for this thesis project.

Typography examples such as Hermann Zapf's works also inspired this project. The layouts and use of contrast especially influenced works like Poem 2.

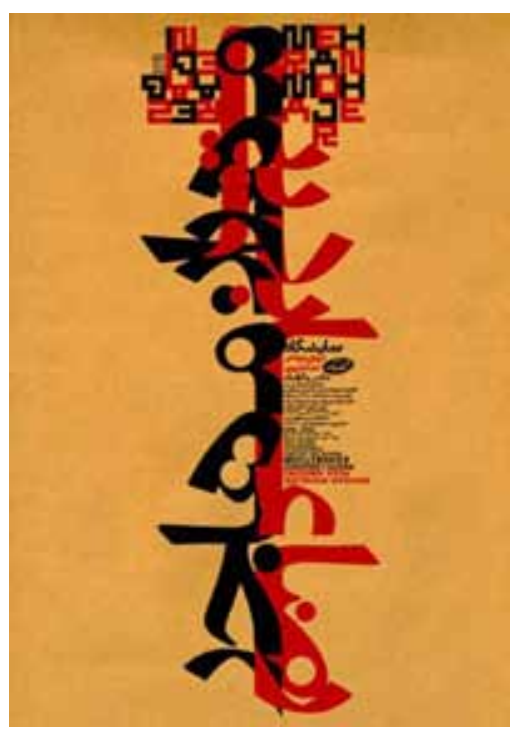

Arabic Poster Design

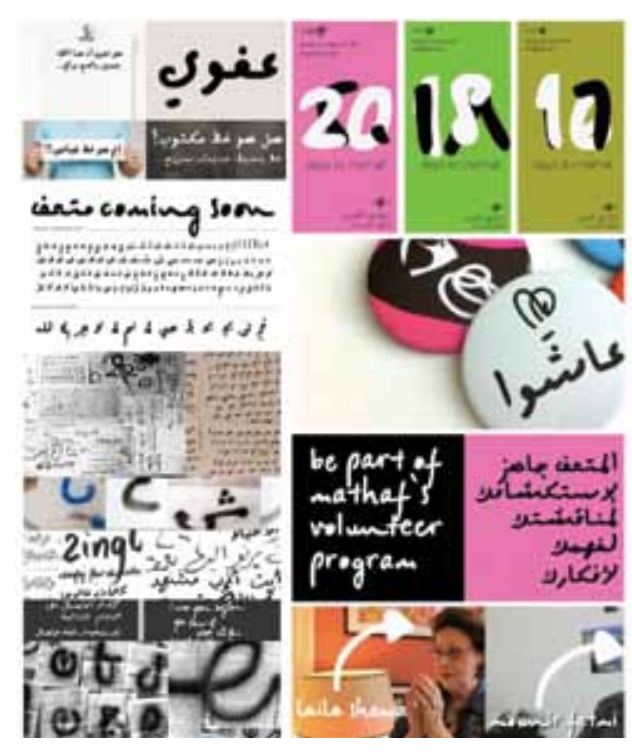

Design for the Arab Museum of Modern Art in Qatar, Tarek Atrissi 


\section{中英文字比较 \\ COMPARISION OFENGLISH AND CHINESE TYPOGRAPHIES}

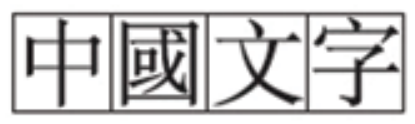

Typography
Belonging to two different language families, English and Chinese have many significant differences. Linguistically, English is an alphabetic language based on signs that represent sounds; Chinese, however, is ideographic. Each Chinese character represents an idea and a sound. Chinese character is the semantic equivalent of a word in the English language. In the Chinese language, a character is the smallest semantic unit, which could be a 'word' by itself, or in combination with other characters form longer terms. A number of basic strokes are used to construct each character. More complex characters are made up of a several basic component parts. A typical character set for a standard Chinese font may consist of 37,000 individual characters which is much more complex than English font consisting usually dozens not thousands. The ideographic nature of Chinese characters means that it is a very compact language. A passage of English text when translated into Chinese often takes up less space. ${ }^{1}$

1 Keith Tam, Typographic bilingualism: a framework for the coexistence of Chinese \& English texts, 2007. 


\section{Space, Kerning and Punctuation}

The most basic anatomical difference between Chinese

characters and Latin typography is that Chinese characters are monospaced while Latin letters are proportionally spaced. English words have different lengths and are separated by word spaces. Every Chinese character occupies exactly the same amount of space, with no word spaces.

Kerning needs to be considered for big texts in English, but Chinese does not have a problem with kerning.

Punctuation marks occupy one full character width each in Chiense. English punctuation, however, takes one letter space. A single space after the period is commonly used in most newspapers, magazines, and similar media.

\section{Ascenders, Descenders and Case}

Latin letters have ascenders and descenders; Chinese characters, however, do not have ascenders and descenders nor upper and lowercase. Every Chinese character is contained within an 'em-box', the equivalent of an em square in Latin fonts. The type designer has to decide how much of the em-box is utilized by the character on average. 

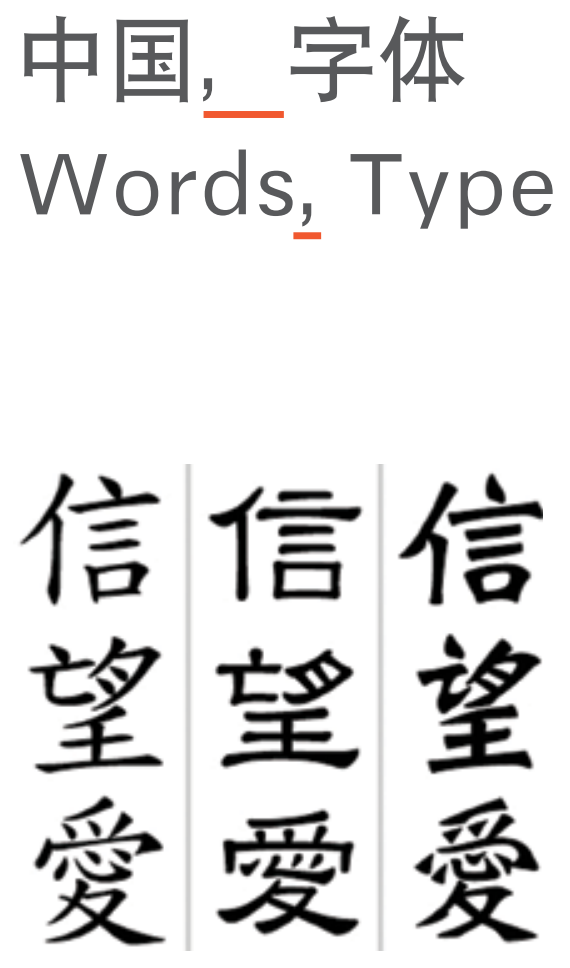

Chinese written vertically from top to bottom and right to left

\section{Sizes and Leading}

The default English type size in many software applications is $12 \mathrm{pts}$. Although this generally creates readable type on screen displays, 12 point text type usually looks big and horsey on a printed page. Sizes between 9 and 11 pts are common for printed text. ${ }^{2}$ Default Chinese type size in Microsoft Word is 10.5 pts. Sizes between 7.87 pts (六号) and 13.75 pts (四号) are common for Chinese printed text. Default line spacing is 100\%. ${ }^{3}$ In most English page layout programs, the default line spacing is $120 \%$, or slightly greater than the cap height. ${ }^{4}$

\section{Reading Order}

Each Chinese character is a self-contained unit and of the same width, so it could be written both vertically and horizontally. Traditionally Chinese is written vertically from top to bottom and right to left. Horizontal setting of Chinese text appeared around the turn of the twentieth century through Western influences. Horizontal settings running from right to the left is also possible, but is not commonly used nowadays.

\section{Justification}

Justified type has been seen in English publications, such as newspapers, books and magazines. Texts flush on both the left and right margins. Used well, justified type can look clean and sophisticated. Except for poetry, continuous Chinese text

2 Ellen Lupton, Thinking with Type: A Critical Guide for Designers, Writers, Editors, \& Students, Princeton Architectural Press, New York, 2004, P37. 3 Rules for Printed Text, http://www.cnpp86.com/bbs/dispbbs. asp? boardID=2\&ID=926\&page $=1$.

4 Ellen Lupton, Thinking with Type: A Critical Guide for Designers, Writers, Editors, \& Students, Princeton Architectural Press, New York, 2004. 
is almost always typeset justified. There are no rules regarding word breaks at line ends; text should break naturally at the end of a line. It is not customary to begin a line of text with punctuation and not to end a line with an open bracket or quotation mark. Line breaks are forced when these instances occur, or by reducing space around punctuation. The neat alignment of characters across lines of type is only compromised when forced line breaks occur, or when proportionally spaced foreign language words and phrased are mixed into the Chinese text. Paragraphs are customarily indicated by leaving two character spaces on the first line, and/or by inserting additional space between paragraphs.

Generally, traditional horizontal Chinese publications are set to justified left with two character spaces at the beginning of a new paragraph. Nowadays, the rules are not as strict as before, so types are often arranged by following the actual design or layout.

Justified left contexts that strictly follow the traditional setting will normally need to edit the texts to get it correct. This could be very time consuming to typographers. 


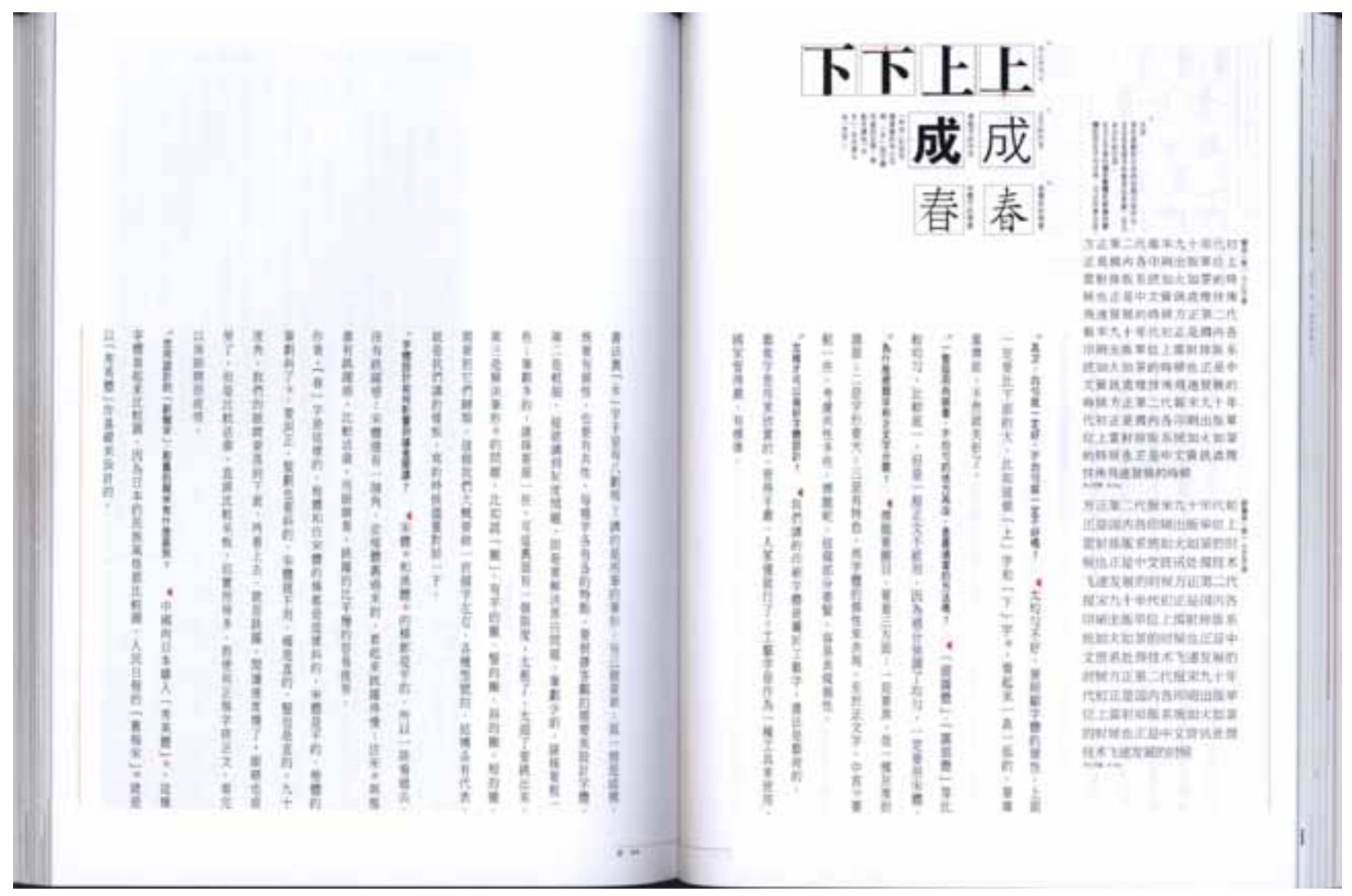

Book Layout from Chinese Typographer, A Character A Life, 2009 


\section{现存问题 \\ PROBLEMS IN ENGLISH-CHINESE
BILINGUAL TYPOGRAPHY}

Hei is a Chinese typeface influenced by Japanese typography. Hei is equivalent with San Serif typeface in English. Here we choose Hei and San Serif typeface Arial for comparison. Chinese types usually look bigger than English, especially when English is in lower case.
Due to the differences existing between English and Chinese typographies, there are many problems that designers need to take into consideration.

\section{Size and Leading}

As discussed in the last chapter, unlike English, Chinese characters do not have ascenders and descenders nor upper and lowercase. That means the $\mathrm{x}$-height of Chinese character is the same as its cap height which is bigger than English types.

双语设计 Bilingual Typography

Hei ( size 34 pts)

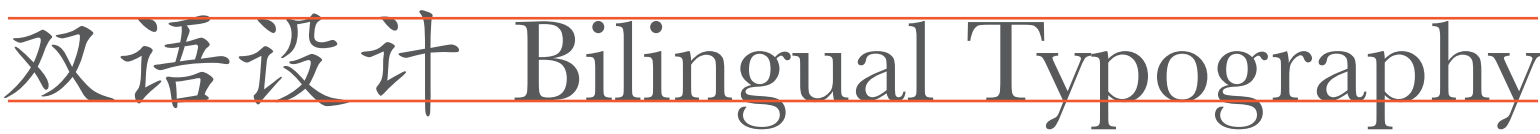

Kai ( size 34 pts)

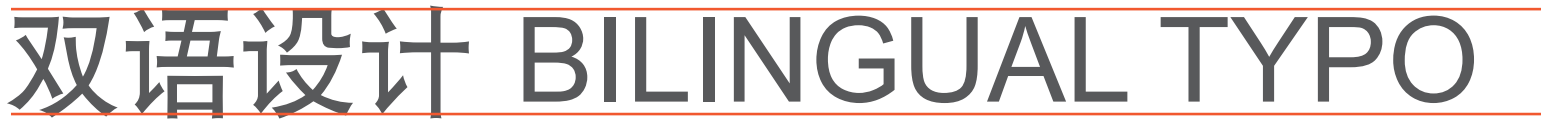

Hei ( size 34 pts)

Arial ( size 34 pts)

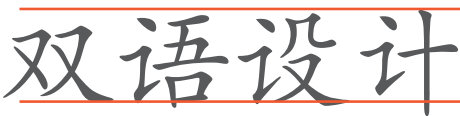

Kai ( size 34 pts)

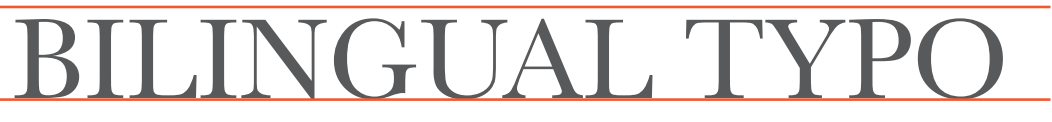

Baskerville ( size 34 pts) 
Typography is one of the most important and complex aspects of visual communication. In short, typography can be described as 'language made visible'. While written language is a way to capture the transient verbal language into a more permanent form, typography is a visual coding system (or one might call this 'visual language') imposed upon written language that influences how meaning is constituted. Typography functions on denotative as well as connotative levels and operates on conscious as well as subconscious levels. Text, from a visual communication standpoint, can be read, seen, as well as felt. Like any language, the visual language inherent in typography is bound to the cultures within which it operates. Designing with different languages requires not only an acceptable command of the language itself, but also knowledge of the conventions, aesthetic principles and nuances that are indigenous to the culture.

English texts, Typeface: Arial, 8 pts

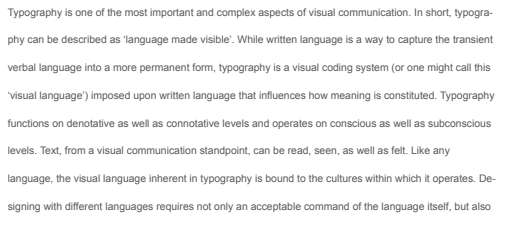

Arial 3 pts
印刷术是视营传达的最重要和最复杂的 方面之一。总之, 排版, 可以被描述

为 “语言可见”。而书面语言是一种更 持久的形式捕捉到短暂的口头语言, 版 式是一个可视化的编码系统（或可称之 为 “视觉语言”）提出书面语言影响的 意思是如何构成的规定。排版功能, 外 延以及内涵水平和意识, 以及作为潜意 识的层面上运作。文字, 从视觉传达的 角度来看, 可以读, 看到的, 以及如认 为。像任何语言, 视觉语言在排版固有 的约束其运作的文化内。设计要求用不 同的语言不仅是语言本身的可接受的命 令, 而且知识的惯例, 审美原则和土著 文化的细微差别。

Chinese texts translated from the English texts on the left in Google Translate, Typeface: Kai, 8 pts

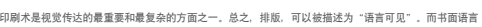

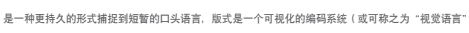

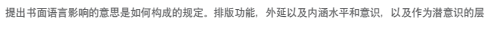

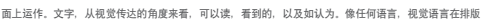

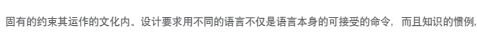

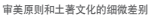

Kai 3 pts
As shown on the left, with the same size and leading, Chinese characters look bigger, and the leading looks smaller. Also the top of the letters is higher than the English paragraph.

\section{Density}

Chinese characters usually have

more complex structures than

English. So it tends to look

heavier than English, even though

stroke weights are similar.

\section{Readability}

Chinese characters have relatively more complex structures than English which makes Chinese relatively more difficult to read.

\section{Length}

When English is translated into

Chinese, the Chinese translation

usually is shorter than English in

length. This tends to make English

look more dominant. ${ }^{1}$

\section{Reading Order}

1 Rules for Printed Text, http:// www.cnpp86.com/bbs/dispbbs. asp? boardID $=2 \& \mid D=926 \&$ page $=1$. 


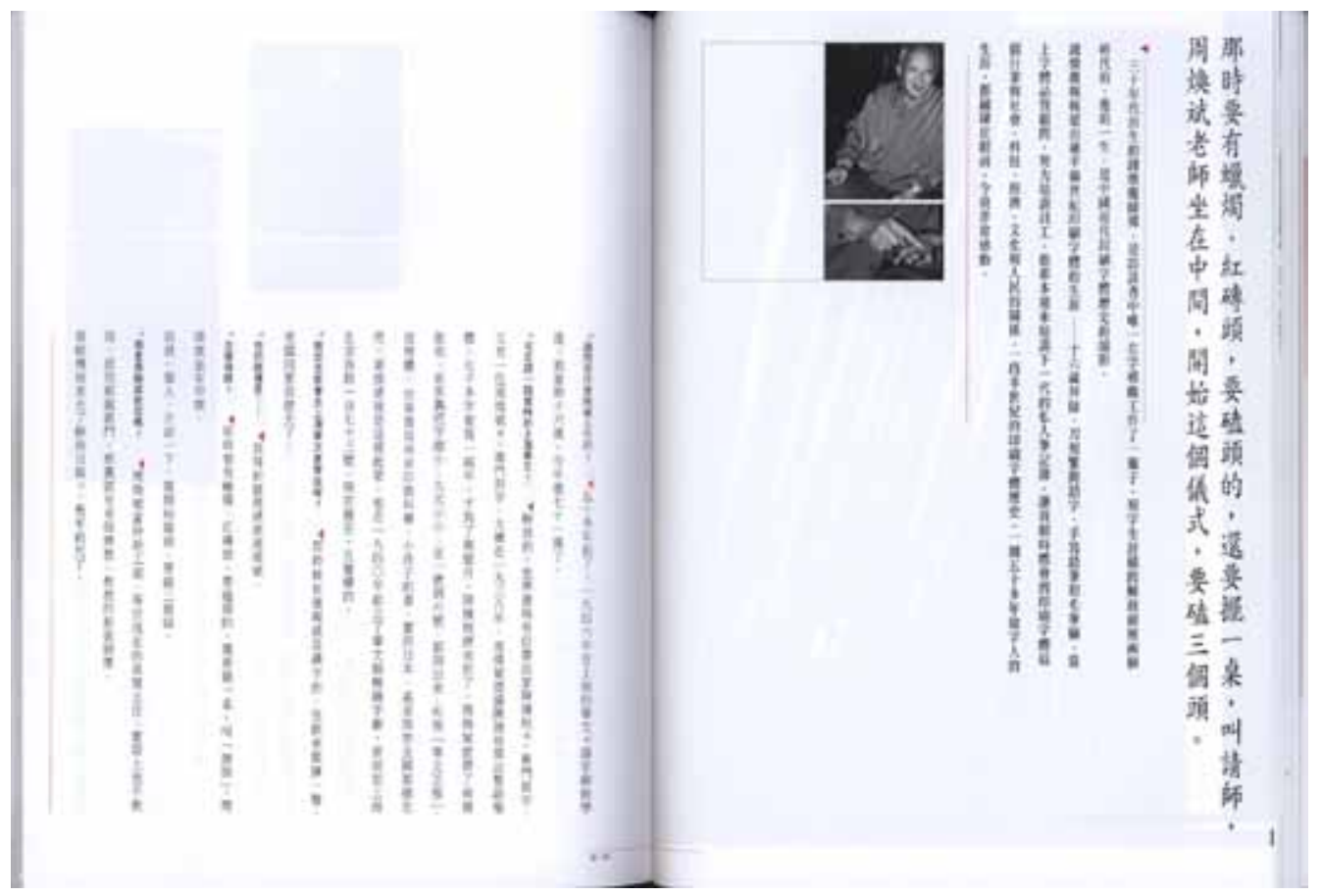

Book Layout from Chinese Typographer,

A Character A Life, 2009

\section{Reading Order}

English reads from left to right and top to bottom. Modern Chinese has the same reading order as English. But traditional Chinese can be written right to left, also from top to bottom, vertically. Some publications still need to be read in the traditional way. Some publications use both. Different reading order can make the bilingual design difficult in terms of keeping information parallel layout balanced.

\section{Flexibility}

As discussed earlier, Roman letters form words and can be hyphenated when reaching the end of a line. For Chinese, in order to accommodate the wording, a designer needs to know where in the language or word he should break the Chinese character to the next line and when it should be kept together. That means Chinese is not as flexible as English, and it makes bilingual typography difficult. 


\section{平衡两种文字 \\ BALANCING THETWO TYPOGRAPHIES}

For bilingual design, it is very common that English and Chinese

play equally important roles on a

page. In this case, balancing the

two typographies is important.

\section{Balancing Size and Readability}

As discussed before, Chinese

types usually look bigger than

English. Therefore, in order to

make them look same in size,

the Chinese font size needs to be

decreased. There are some exam-

ples on the right that show how

much we should decrease.

A size 8 of Hei looks bigger than

Arial in the same size. Size 6 of

Hei looks more close to the Arial

size 8 , however, is a little hard to

read. Therefore, a size 7 of $\mathrm{Hei}$ is

the best match to a size 8 of Arial.

This is only an example of the size

exercise for the choice of Chinese

type size. The adjustment for the

size should be variable due to the

text sizes.
Typography is one of the most important and complex aspects of visual communication. In short, typography can be described as 'language made visible'. While written language is a way to capture the transient verbal language into a more permanent form, typography is a visual coding system (or one might call this 'visual language') imposed upon written language that influences how meaning is constituted. Arial 8 pts

Typography is one of the most important and complex aspects of visual communication. In short, typography can be described as 'language made visible'. While written language is a way to capture the transient verbal language into a more permanent form, typography is a visual coding system (or one might call this 'visual language') imposed upon written language that influences how meaning is constituted.

Arial 8 pts

Typography is one of the most important and complex aspects of visual communication. In short, typography can be described as 'language made visible'. While written language is a way to capture the transient verbal language into a more permanent form, typography is a visual coding system (or one might call this 'visual language') imposed upon written language that influences how meaning is constituted.

Arial 8 pts
印刷术是视觉传达的最重要和最复杂的 方面之一。总之, 排版, 可以被描述 为 “语言可见”。而书面语言是一种更 持久的形式捕捉到短暂的口头语言, 版 式是一个可视化的编码系统 (或可称之 为 “视觉语言” ) 提出书面语言影响的 意思是如何构成的规定。排版功能, 外 延以及内涵水平和意识, 以及作为潜意 识的层面上运作。

Hei 8 pts

印刷术是视觉传达的最重要和最复杂的方面之 一。总之, 排版, 可以被描述为 “语言可见” 。而书面语言是一种更持久的形式捕捉到短暂 的口头语言, 版式是一个可视化的编码系统 ( 或可称之为 “视觉语言” ) 提出书面语言影响 的意思是如何构成的规定。排版功能, 外延 以及内涵水平和意识, 以及作为潜意识的层 面上运作。

Hei 7 pts

印刷术是视觉传达的最重要和最复杂的方面之一。总 之, 排版, 可以被描述为 “语言可见”。而书面语言 是一种更持久的形式捕捉到短暂的口头语言, 版式是 一个可视化的编码系统 (或可称之为 “视觉语言”) 提出书面语言影响的意思是如何构成的规定。排版功 能, 外延以及内涵水平和意识, 以及作为潜意识的层 面上运作。

Hei 6 pts 


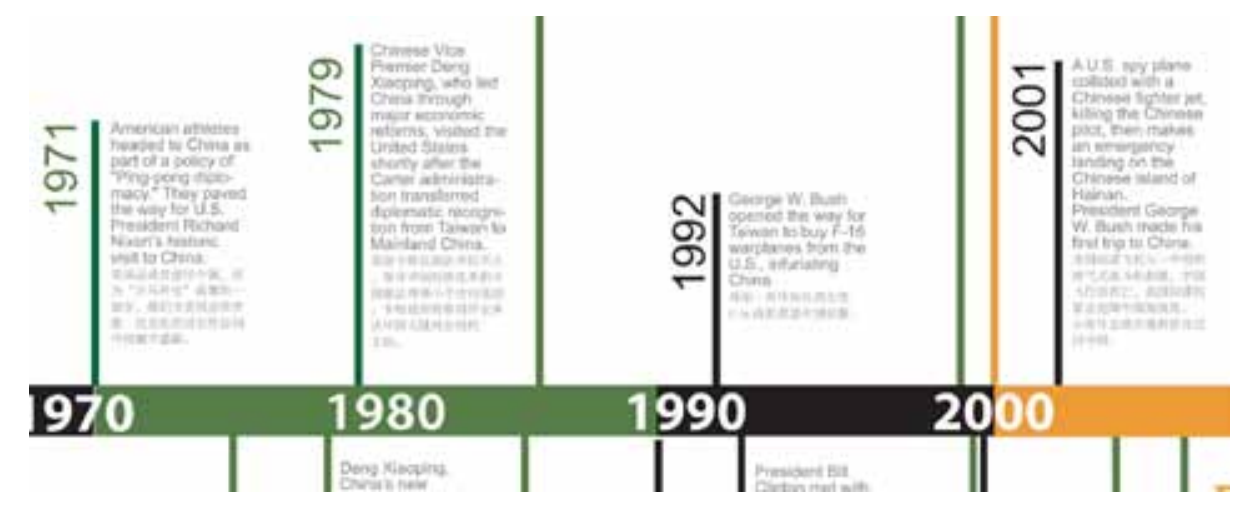

\section{Paragraph Length Treatment}

Since Chinese is usually shorter than English translation, a designer needs to consider balancing the paragraph length in his design. There are several ways to avoid the paragraph length problem.

1. Add graphics to balance the space.

2. Instead of placing English and Chinese texts next to each other, put them in the same column.

3. Avoid parallel layout.

4. Use different column widths and keep the same paragraph length. (See the example on the right)

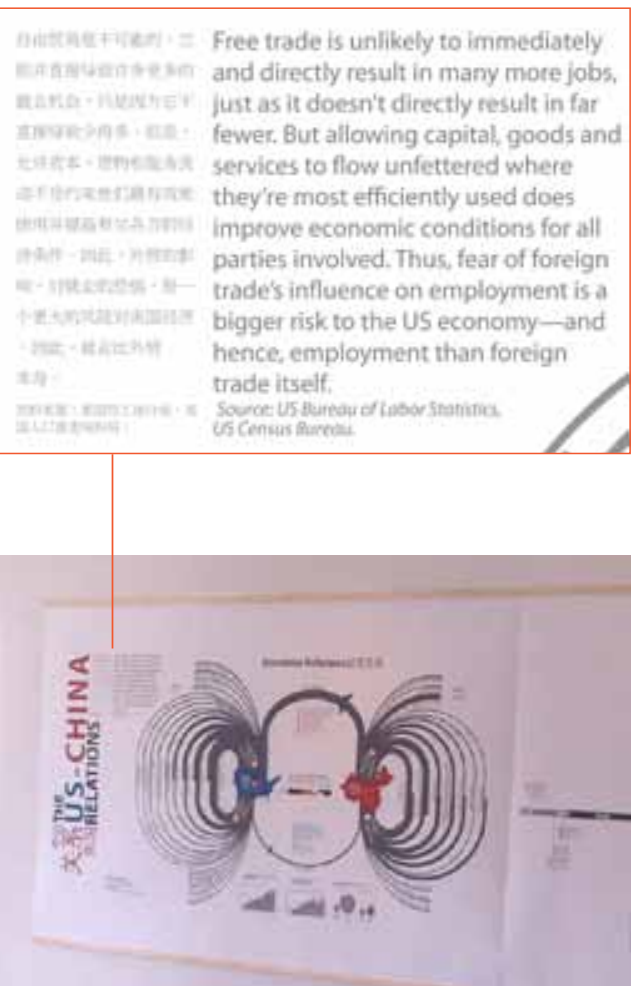

Details, US-China Relations, Bilingual Information Graphics, 142 inches $\times 44$ inches, 2012 


\section{Choosing Fonts}

There are many English and Chinese fonts to choose from. To choose the right ones that match each other and

create harmony is one of the most important things for

bilingual print design.

Usually choosing the typefaces that share similar features can make the bilingual typography more balanced. There are three most commonly used Chinese fonts: Sung (宋), Kai (楷), and Hei (黑). The Sung style, commonly used for continuous text, has thick and thin transitions, similar to seriffed Latin typefaces. It was developed from the Kai calligraphic style by regularising and abstracting its calligraphic features for the sake of speed in carving woodblocks for printing. The Kai type style, directly derived from the Kai brush script, has no Latin equivalent. There is also a Chinese equivalent of san serif typefaces called Hei, literally meaning 'black'. This style was probably imported from Japan in the early twentieth century. ${ }^{1}$

1 Keith Tam, Typographic bilingualism: a framework for the coexistence of Chinese \& English texts, 2007.

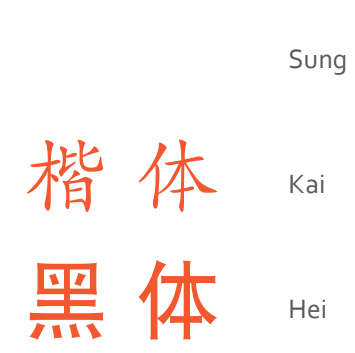

在版式, 字体是一 个字符集的视觉陈 述或解释, 这是他 们的外观。每个字 体的设计, 并正在 不断发展新的, 有 成千上万的存在不 同的字体。

Sung

在版式, 字体是一 个字符集的视觉陈 述或解释, 这是他 们的外观。每个字 体的设计, 并正在 不断发展新的, 有 成千上万的存在不 同的字体。

Hei
In typography, a typeface is the visual representation or interpretation of a set of characters; it is their appearance. Each typeface is designed, and there are thousands of different typefaces in existence, with new ones being developed constantly.

Baskerville

In typography, a typeface is the visual representation or interpretation of a set of characters; it is their appearance. Each typeface is designed, and there are thousands of different typefaces in existence, with new ones being developed constantly.

Helvetica 


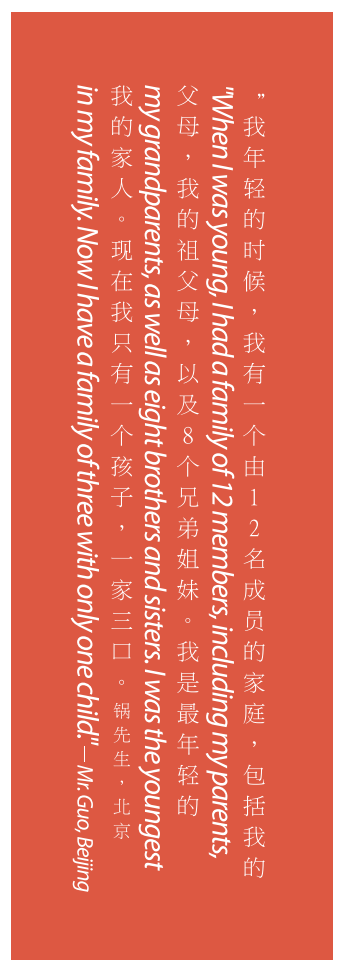

The Changing of Family Structure in China, Detail, 2012

\section{Reading Order Solution}

Chinese can be written right to left and top to bottom, which is different from English. When Chinese is written this way, balancing the two typographies could be difficult. When there is not a big amount of text, English can be embedded into Chinese. Since most Chinese characters have the same cap height, it is easy to form parallel lines where English can be embedded.
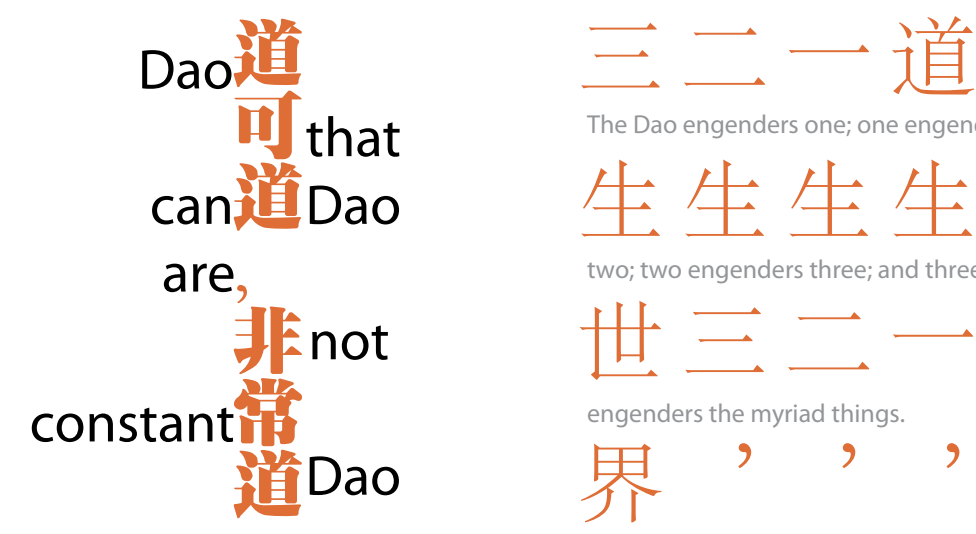

The Dao engenders one; one engenders

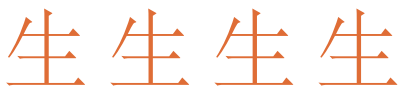

two; two engenders three; and three

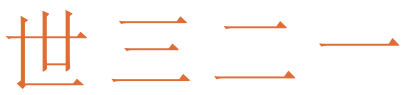

engenders the myriad things.

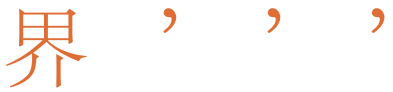

Details, Ways of Tao, , Bilingual Accordion Book, 6.5 inches $\times 6.5$ inches, 18 panels, 2011 
Besides creating balance between English and Chinese

typography, there are many other purposes for combining the two written languages.

\section{Creating Hierarchy}

In many situations, bilingual designers need to put emphasis on the dominant language of the audience. For example, Urban China magazine designed by Hendrik-Jan Grievink, is in Chinese with select texts published in English. The magazine uses both English and Chinese, but emphasizes Chinese more due to its main audiences being Chinese.

Sometimes in order to create an interesting visual language,

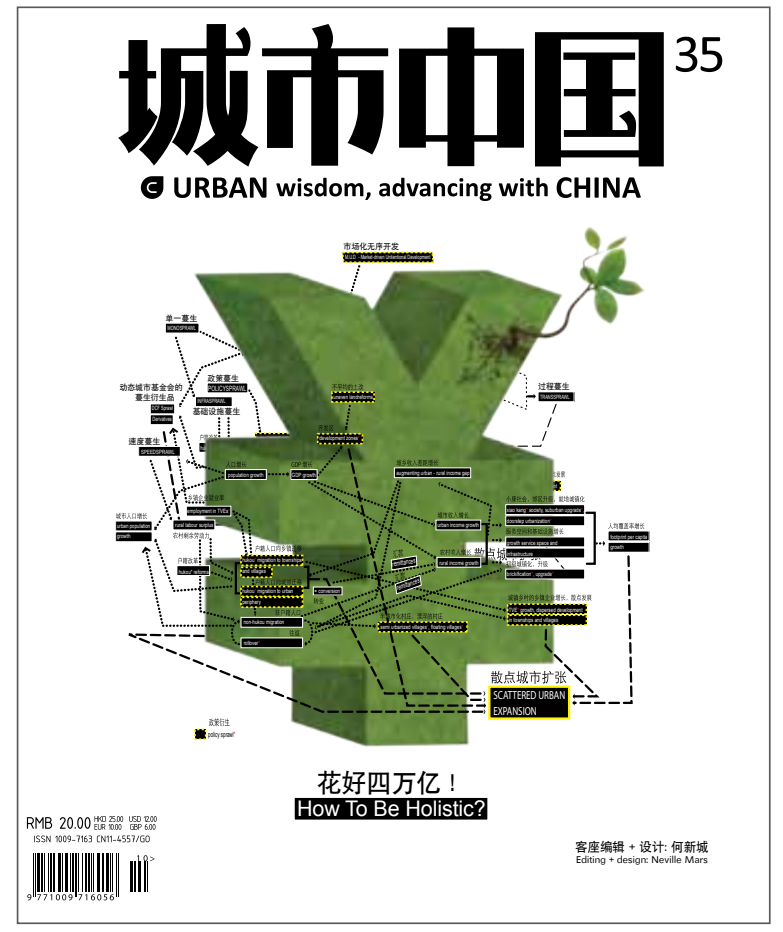

Urban China Magazine 35, Cover 
a designer also needs to emphasize one language and minimize the other.

For example Home (家). I did not intend to emphasize Chinese on this work, but in order to create hireachy I made the Chinese characters much larger than the equivalent English text. This also happens to the following examples: New Changes in China's Social Class Structure, Modern China's Generation Gap and Self.

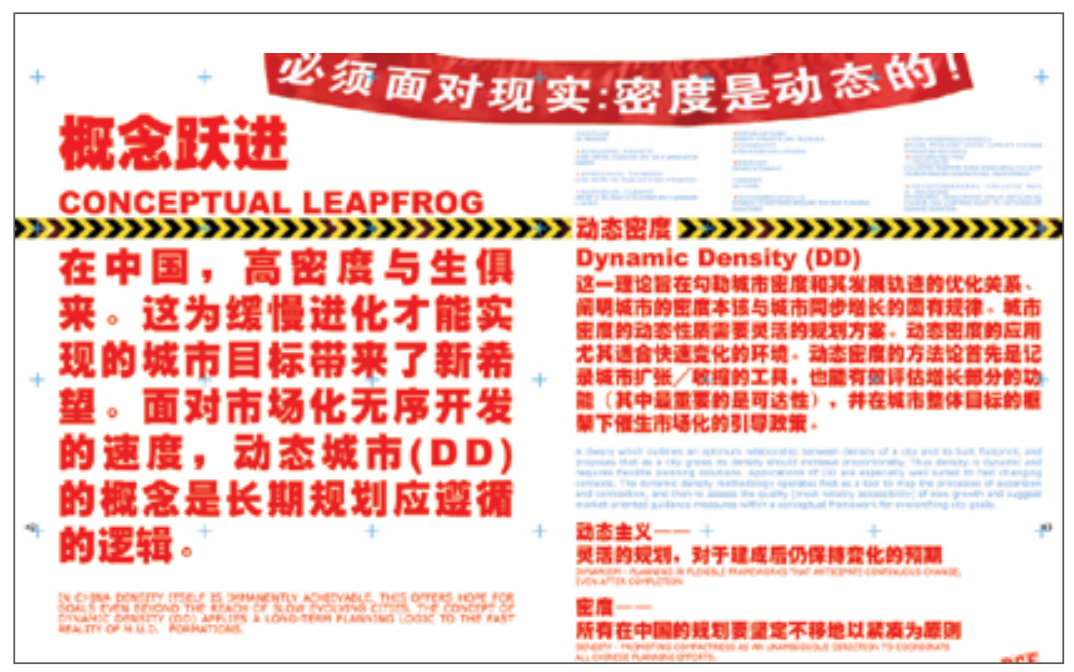

Urban China Magazine 35, spread 


\section{Type as Image}

Like English typography, bilingual typography can also work together as images. A good use of type as image can create great visual effects and help communication between the design and audiences as well. In the work of "Home", a big Chinese character "家" is arranged in the middle of the design. Light yellow color and a out glowing effect create an image like a light.

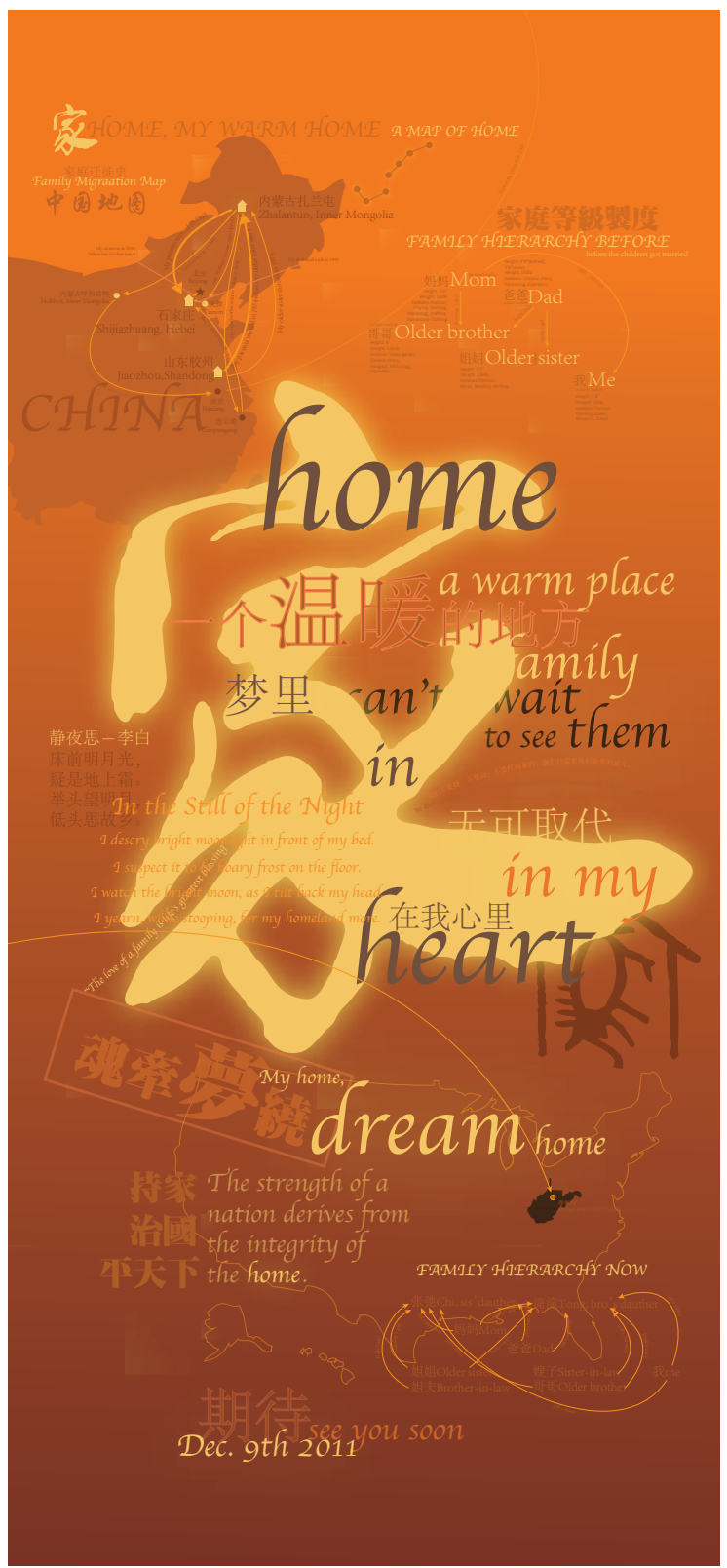

Home, Bilingual interactive poster, 41 inches $\times 18$ inches, 2011 


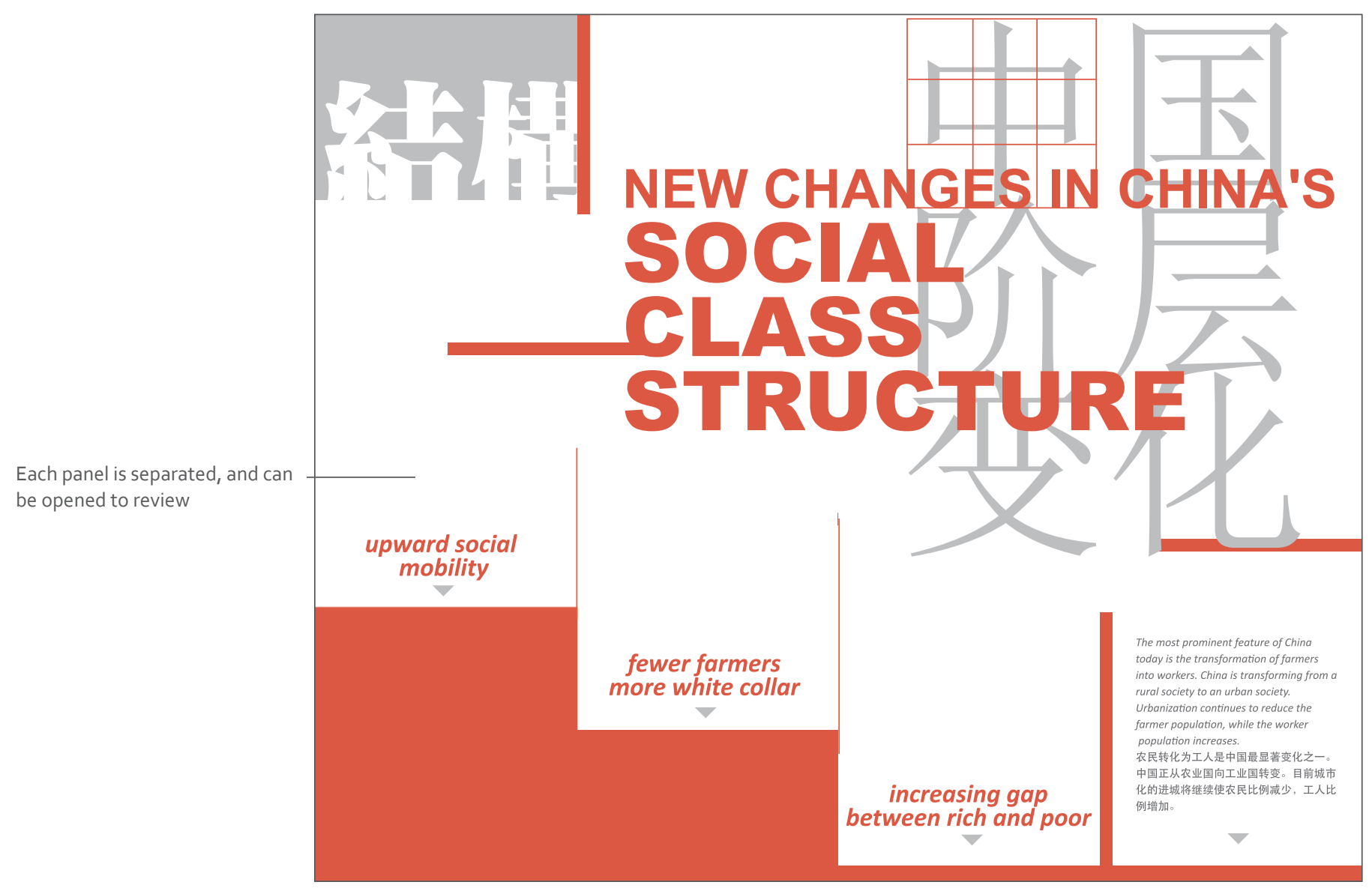

New Changes in China's Social Class Structure, Bilingual Interactive Poster, 58 inches x 44 inches, 2012 


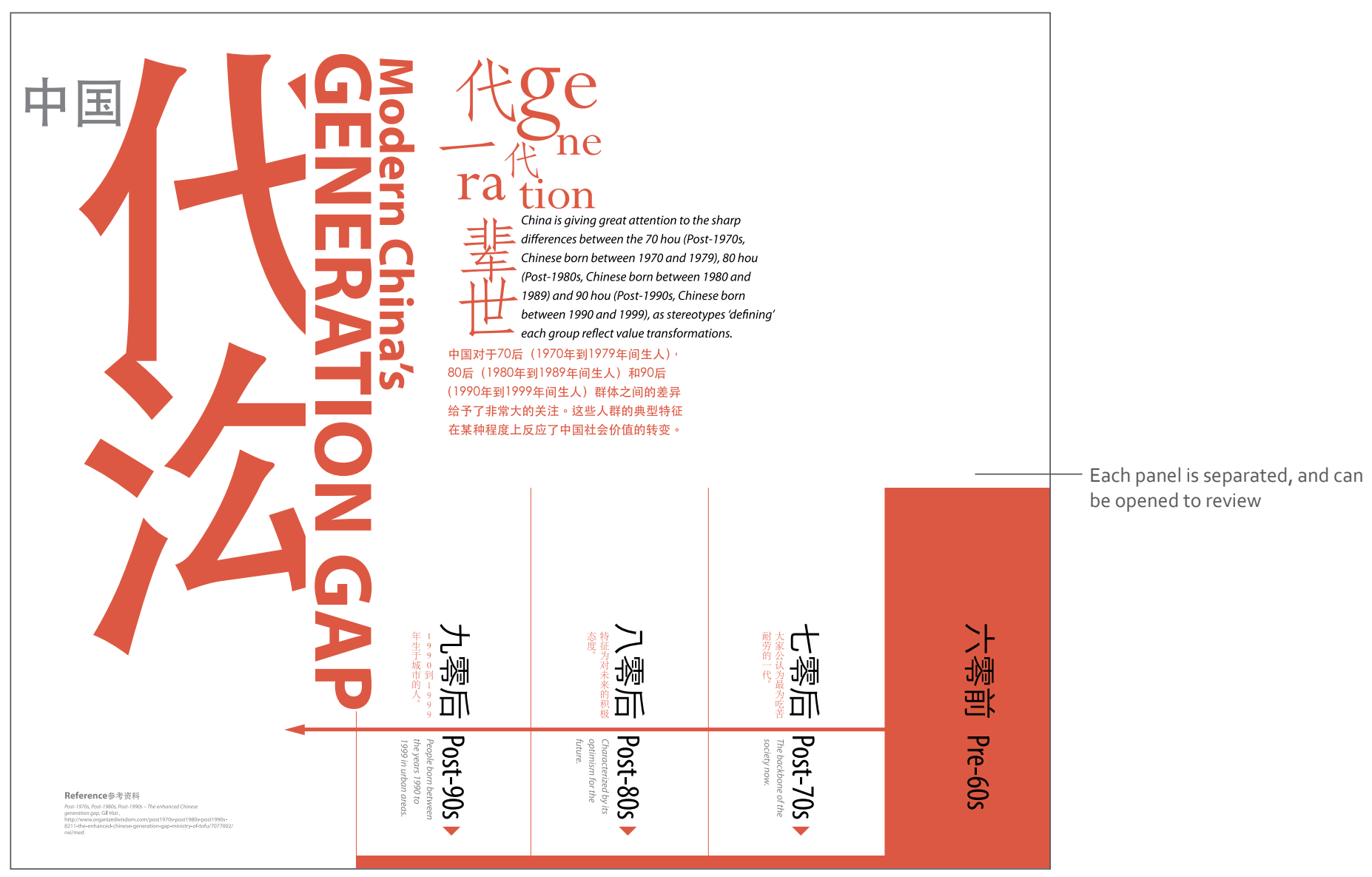

Modern China's Generation Gap, Bilingual Interactive Poster, 58 inches x 44 inches, 2012 


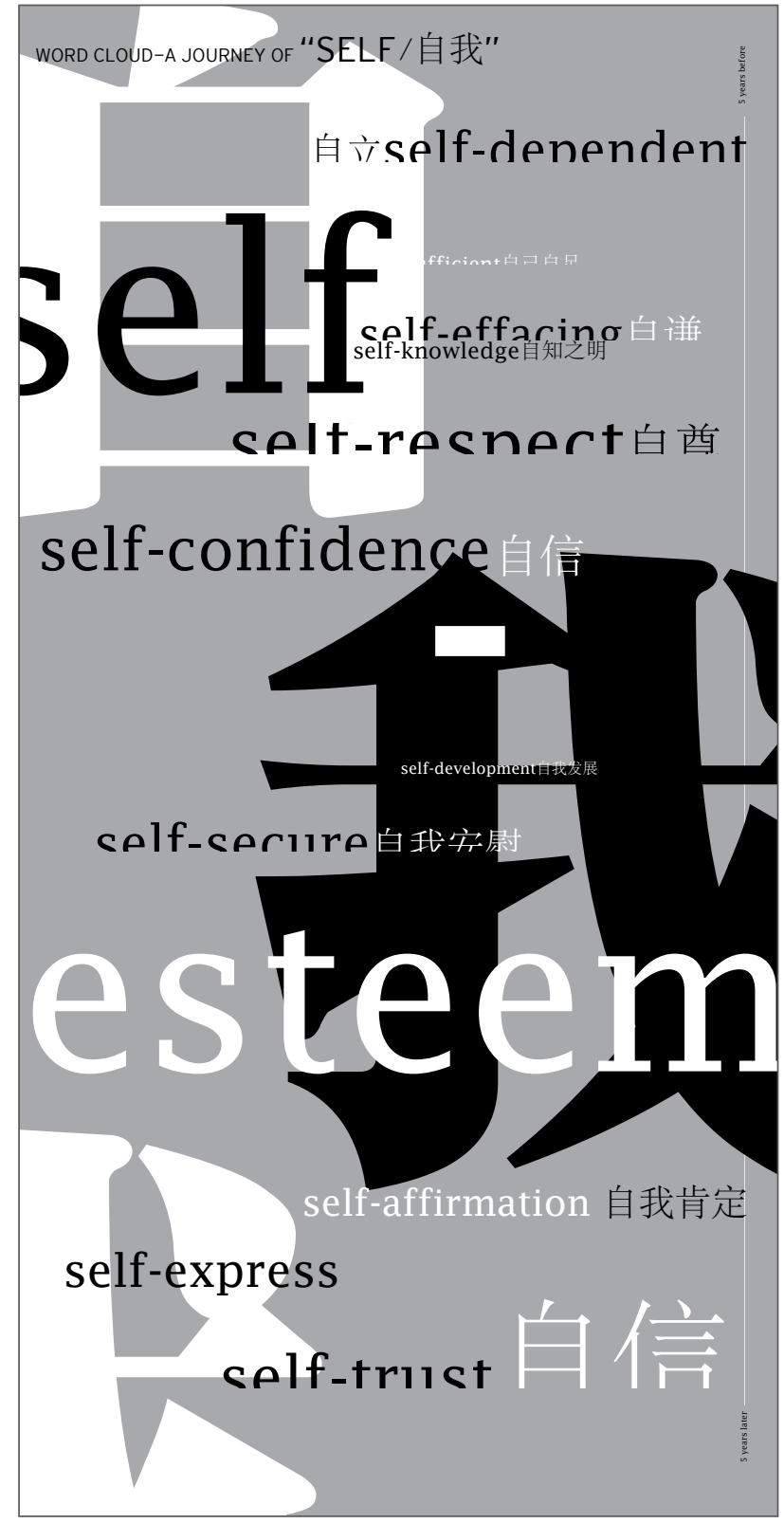

Self, interactive poster, 44 inches $\times 18$ inches, 2011 


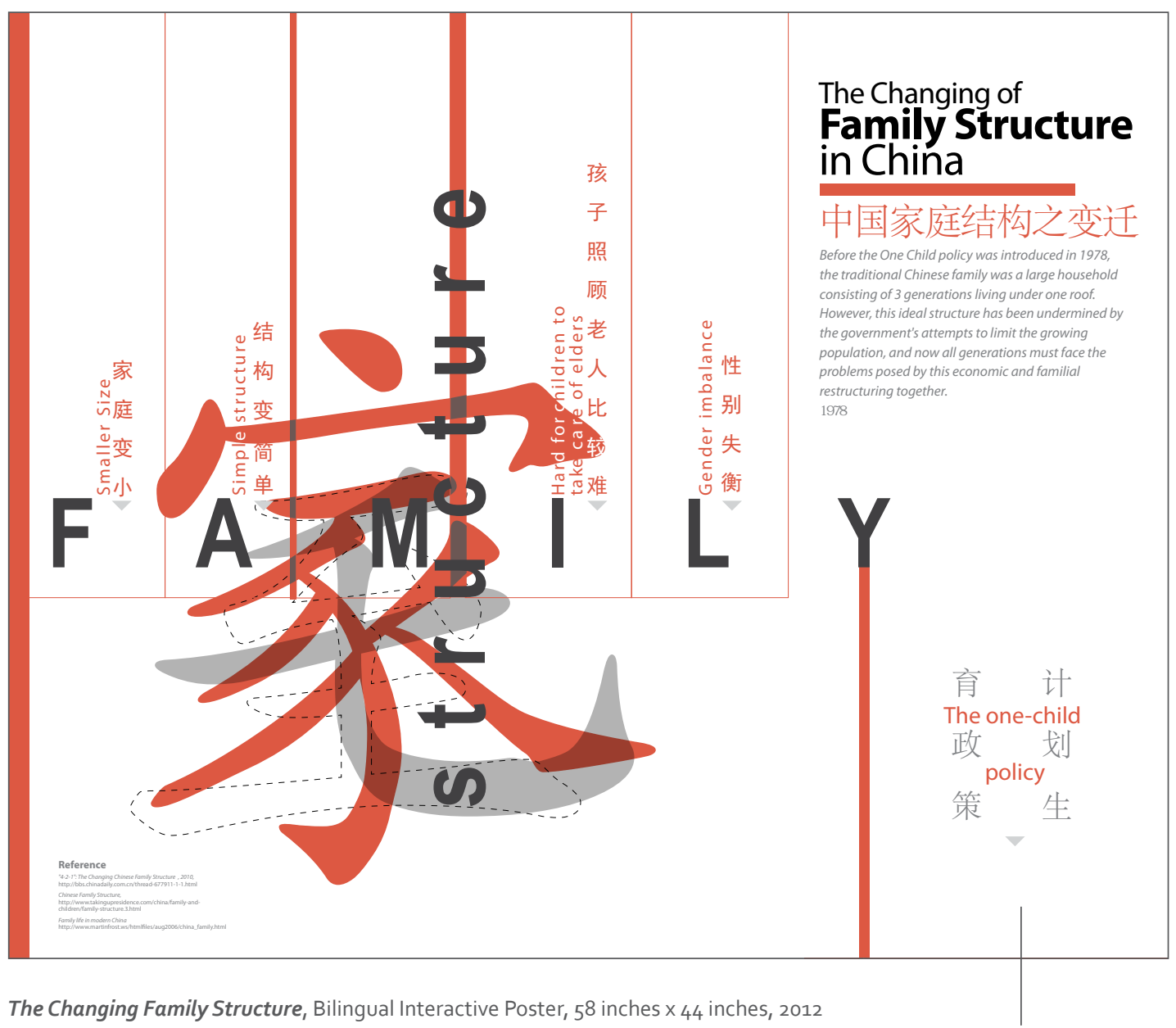

Each panel is separated, and can be opened to review 


\section{Sharing Mutual Parts}

Some Chinese and English typefaces have similar weights, which makes it possible for the two typefaces combine together to form a new look while the two can still be recognizable. Take the bottom left for example, I combine the top part of (道) and the bottom part of letter "a" and "o". The two words form a new form, yet are still recognizable.

\section{Embedding Types in Each Other}

Sometimes, English and Chinese can embed to each other and still recognizable. Take the image on the top right, for example Chinese character is embedded in English word "Tao" and create an image.

\section{Transparency}

When the two type weights are similar, adding a transparency could make the two still readable and create a new form. (see image on the bottom of page 33)

\section{Others}

There are also other ways to combine the two texts.

For example, the image on the right bottom uses
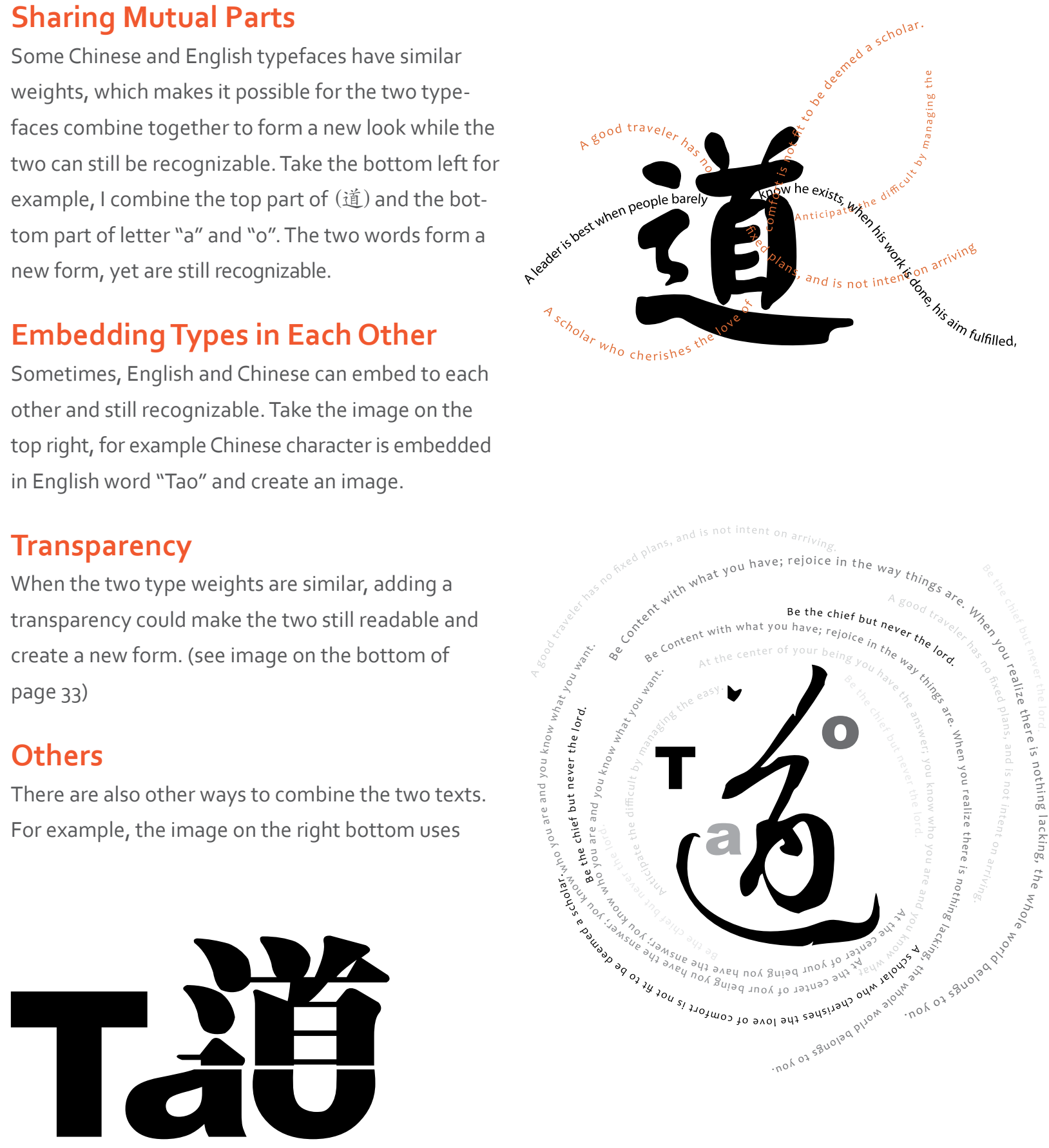

Details, Ways of Tao, , Bilingual Accordion Book, 6.5 inches $\times 6.5$ inches, 18 panels, 2011 
a big Chinese charactor "道" and small English text goes around it aligning with the strokes of the Chinese character. It also conveys the meaning of "no specific rules of Tao". In the image on the right, a small block of English texts form a red block in front of the Chinese character. A hierarchy is formed and readability is kept.

For the image on the bottom right, the heart shape as a background is formed by English texts; white spaces inside are Chinese characters.

One language can also be the background of the other, with appropriate leading; the two typographies can still be readable as the example on the middle right.
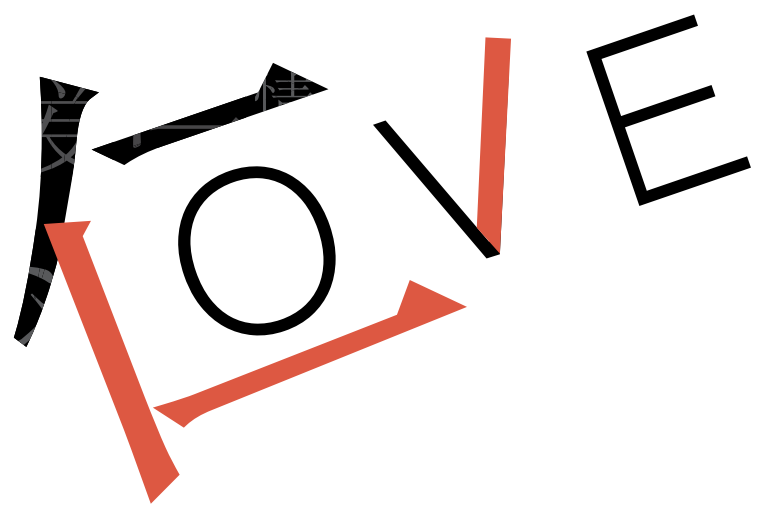

Love, Illustration, 6 inches $\times 6$ inches, 2012
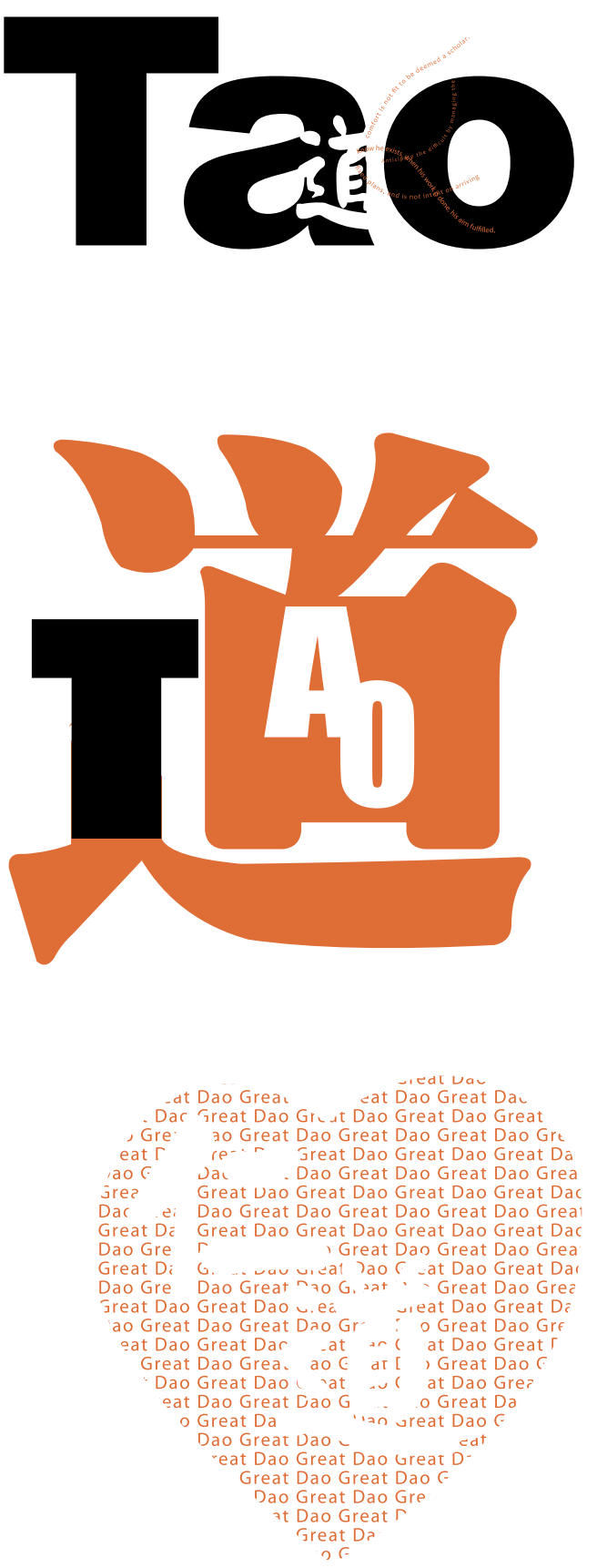

Details, Ways of Tao, Bilingual Accordion Book, 6.5 inches $\times 6.5$ inches, 18 panels, 2011 


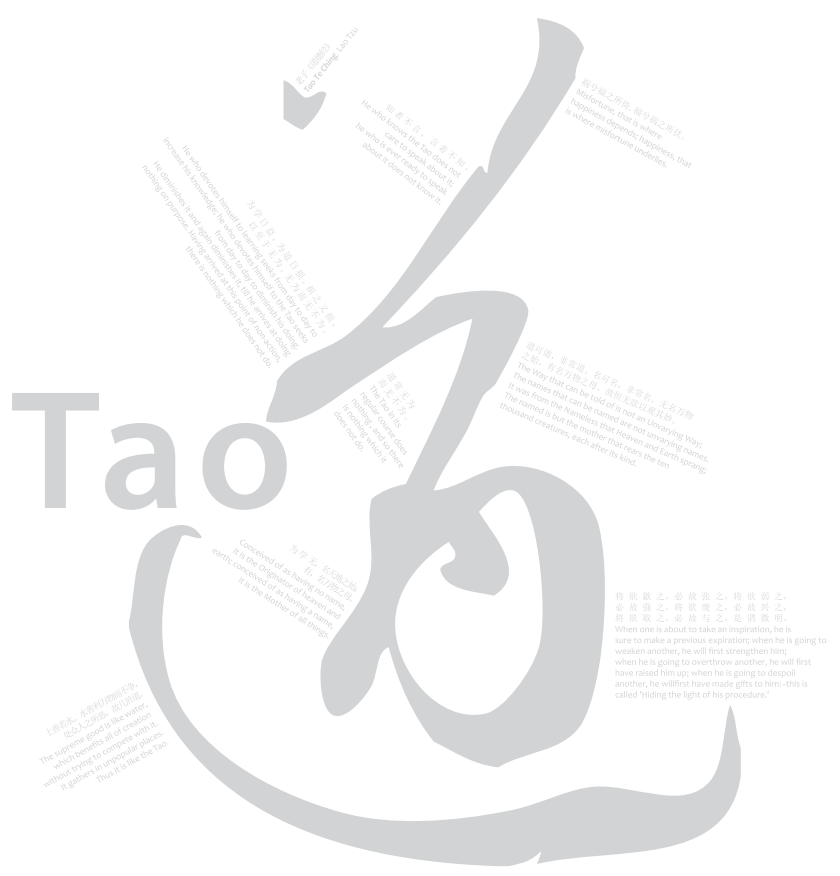

Detail, Ways of Tao Installation, 2012

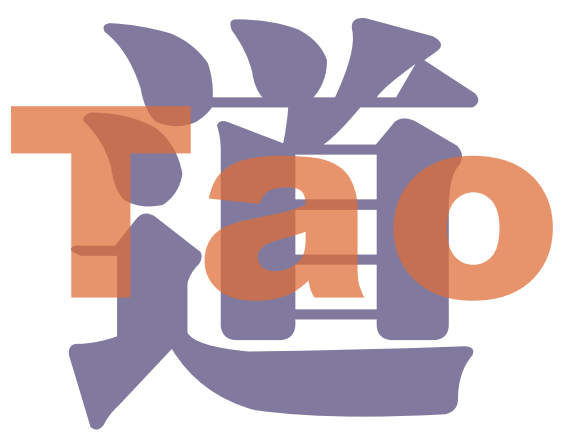

Detail, Ways of Tao, , Bilingual Accordion Book, 6.5 inches $\times 6.5$ inches, 18 panels, 2011 


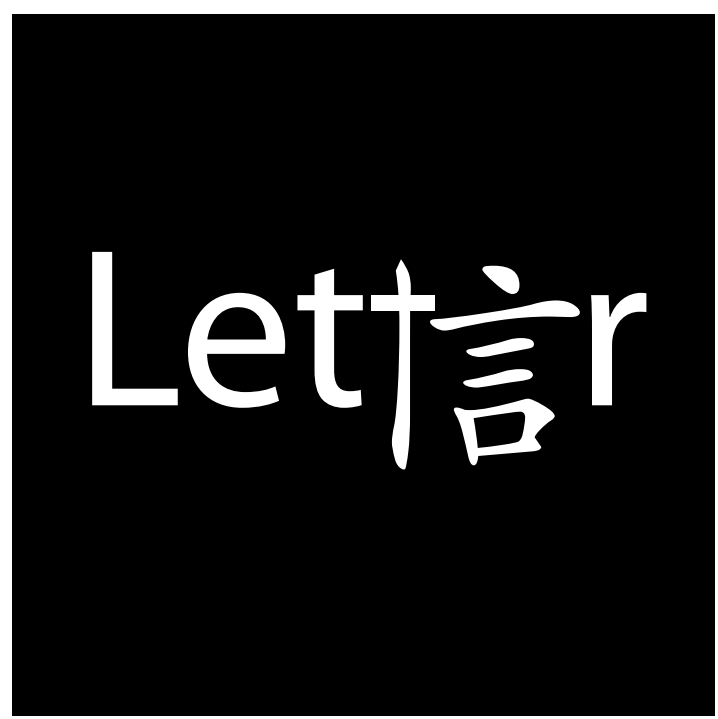

Letter, Illustration, 6 inches $\times 6$ inches, 2012

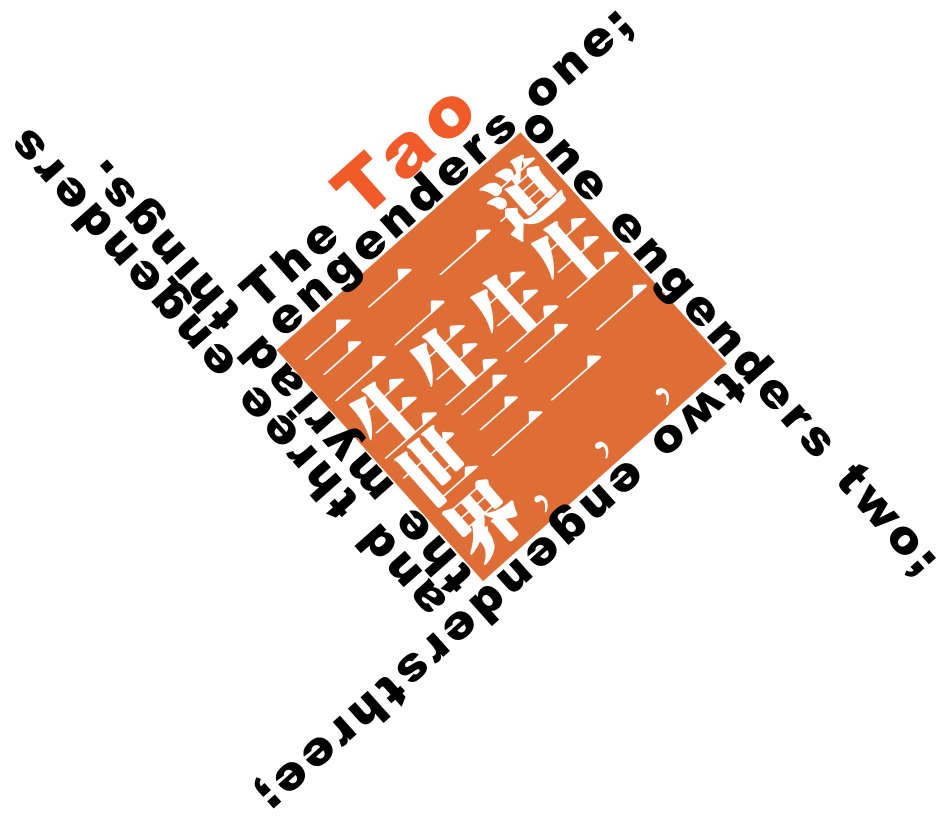

Detail, Ways of Tao, , Bilingual Accordion Book,

6.5 inches $\times 6.5$ inches, 18 panels, 2011 


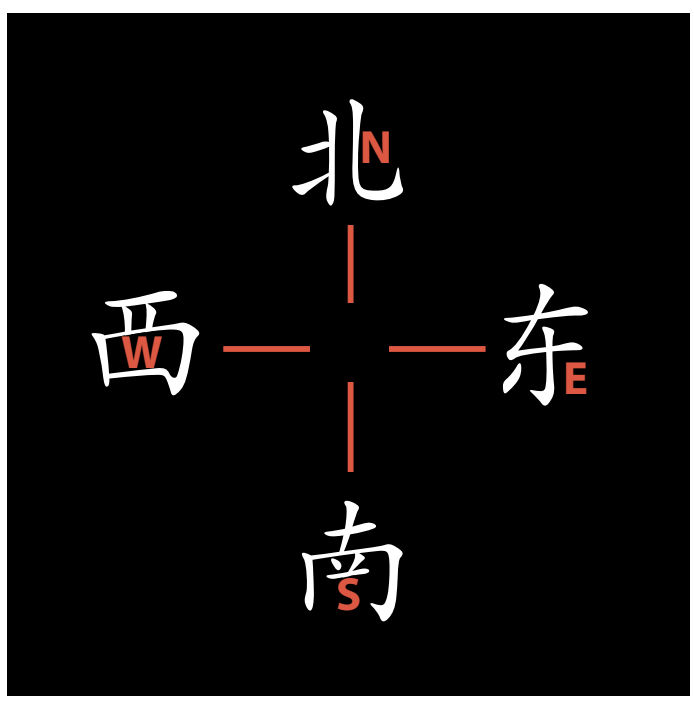

$E, W, S, N$, Illustration, 6 inches $\times 6$ inches, 2012

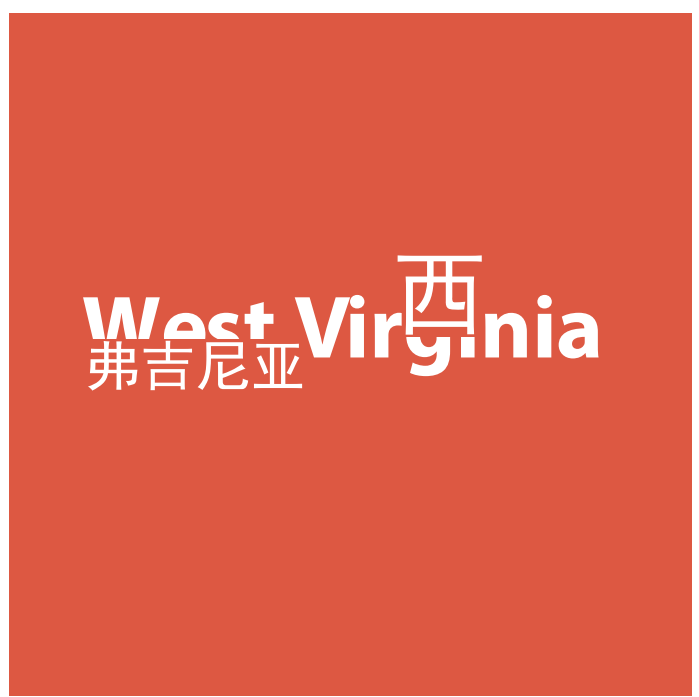

West Virginia, Illustration, 6 inches $\times 6$ inches, 2012 


\section{结论及展示}

\section{CONCLUSION AND DEMONSTRATION}

Due to the differences between English and Chinese typographies, bilingual design is challenging. Among the challenges, balancing size and paragraph length are two of the most important ones. Chinese characters usually look bigger than English words since they have bigger cap heights. Therefore, for large amount of text, designers need to reduce Chinese type size. For a size 12 English text, recommended Chinese size is 9-10 depending on the fonts designers choose. Chinese texts are usually shorter than English translation. So for small amount of text, English tends to look more dominant than Chinese. In this case, designers need to consider enlarging the Chinese text to the size that makes the Chinese equally important as the English.

Chinese is usually shorter than English translation, so they may look unbalanced when they are parallel to each other. Decreasing the width of Chinese paragraph and making the paragraph the same length as English is a good way to solve the problem. Also, arrange English and Chinese paragraphs in one column or avoid them placing them parallel is another way to solve the problem. In my thesis project, these methods have been applied to most of the pieces. (See works from page 37 to page 47.) Besides balancing font size and paragraph length, designers also need to be aware of other problems, for instance, italics are very common in English for quotes, names of publications or art works. However, most of Chinese fonts don't have italics like English fonts do. Therefore, designers have to be aware of that and come up with other ways to difference them. In my thesis project, I solved this problem by changing Chinese fonts or sizes to difference them from other texts. (See Thesis Show Description, page 38)

The differences between English and Chinese typographies, however, also provide possibilities for bilingual typography. The thesis project explored some methods that help to achieve the possibilities: 1 . Creating bilingual words by combining English letters and Chinese characters (See Letter, page 34; Love, page 49); 2. Forming meaningful images with the two typographies (See Tao, page 33); and 3. Creating 
sophisticated forms utilizing different reading orders ( See Tao Accordion Book, page 39). These methods focus on creating interesting forms while solving bilingual problems. Most importantly, they add value to bilingual designs, and help audiences to find connections with the languages and improve communication between the audiences and the designs.

Much like languages, bilingual typography means to enhance communication between the audiences and the designs. In order to make the communication easier, I added interactive components to poster New Changes in China's Social Class Structure, Modern China's Generation Gap, and The Changing Family Structure (page 42-page 46). Two pages were used for each poster. On the cover, there are titles, descriptions, and some important information. The information was separated by several cuts. To find out more, people need to flip the slips to see the inside pages. The information on the inside pages are either descriptions, quotes, or stories. They are concise, so that the audience won't lose patience. The interactive component makes the designs more sophisticated and engage the audiences better. Different from the previous posters, the poster Essence Consistent with Nature (page 40) applied a different interactive method. There are texts on both the cover and inside page. Some texts were Chinese and others were English. However, translations can not be found on the same page. Therefore, people have to flip the strips to find out the translations. People who only know one of the languages might want to discover what the messages mean by flipping the strips. People who are bilingual might be interested in how accurate the translations are, so they will want to interact with the poster too.

The thesis project researched methods of English-Chinese bilingual typography design and also how interactive components could help improving the communication with the audiences. The methods could be used in English-Chinese bilingual signage design, print publication, and museum educational materials. Hopefully this study will inspire designers to explore more ways of designing with bilingual typography. 


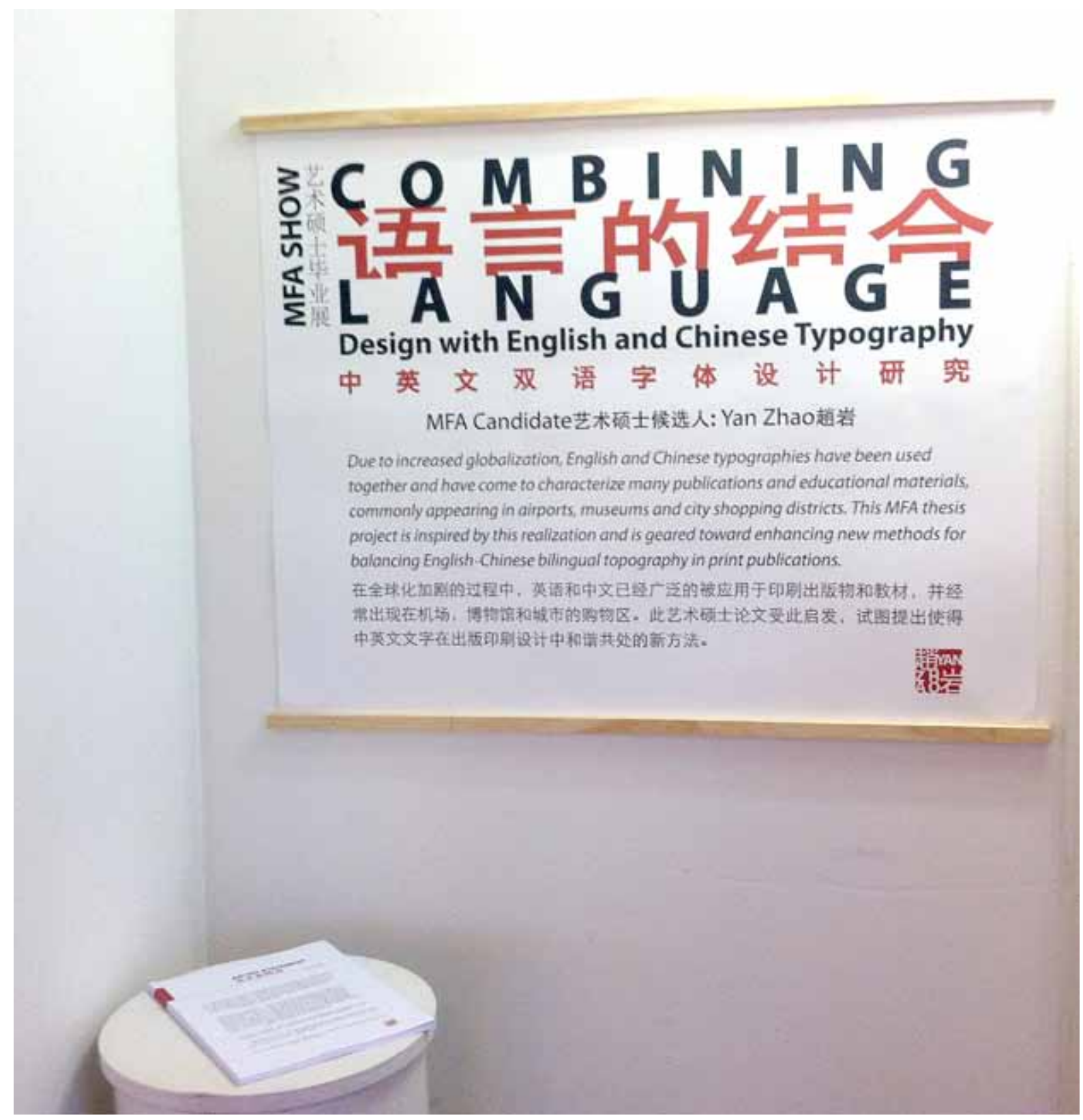

Description of the MFA Thesis Exhibit, 2012 

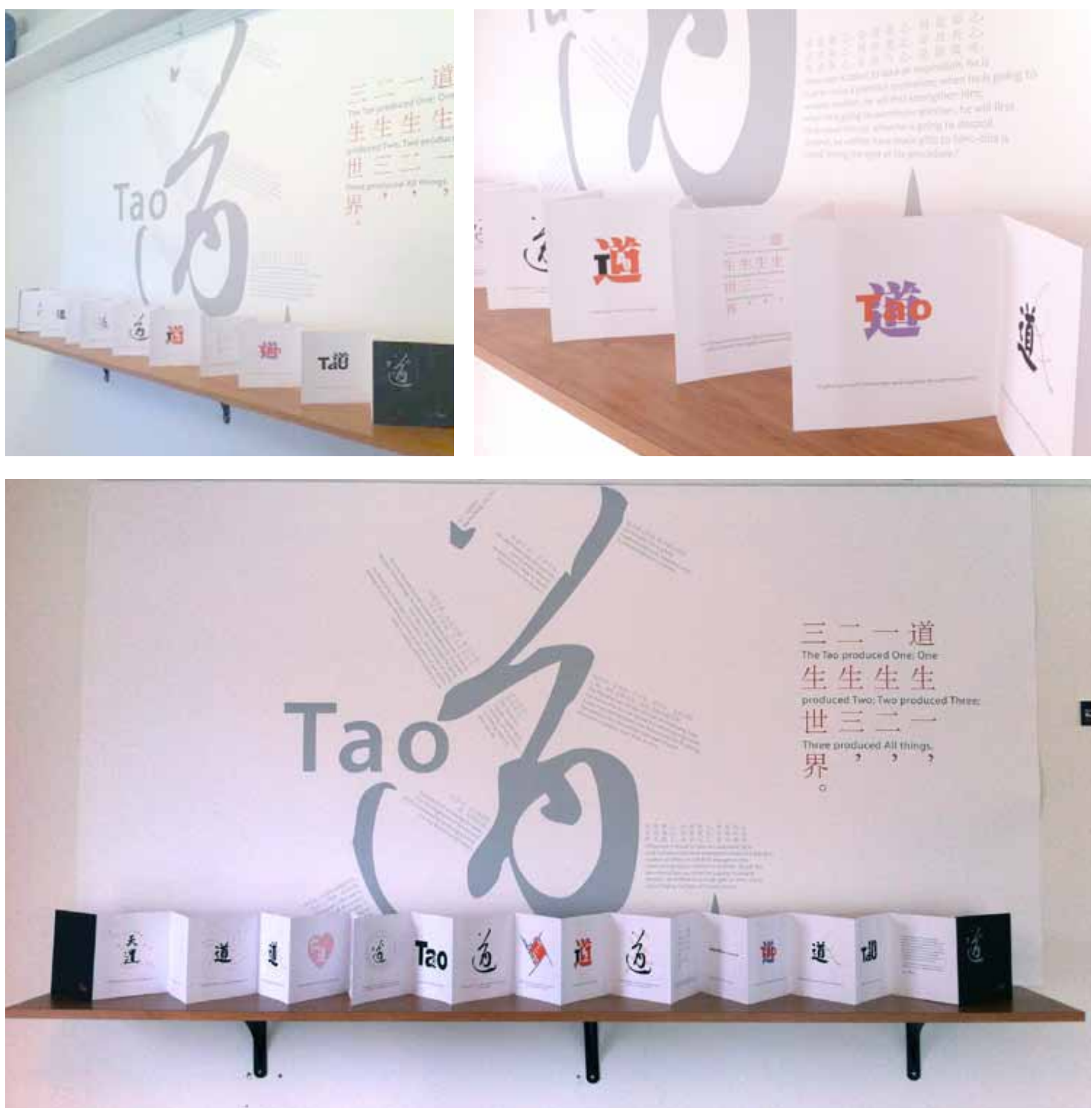

Ways of Tao, , Bilingual Accordion Book, 6.5 inches $\times 6.5$ inches, 18 panels, 2011 

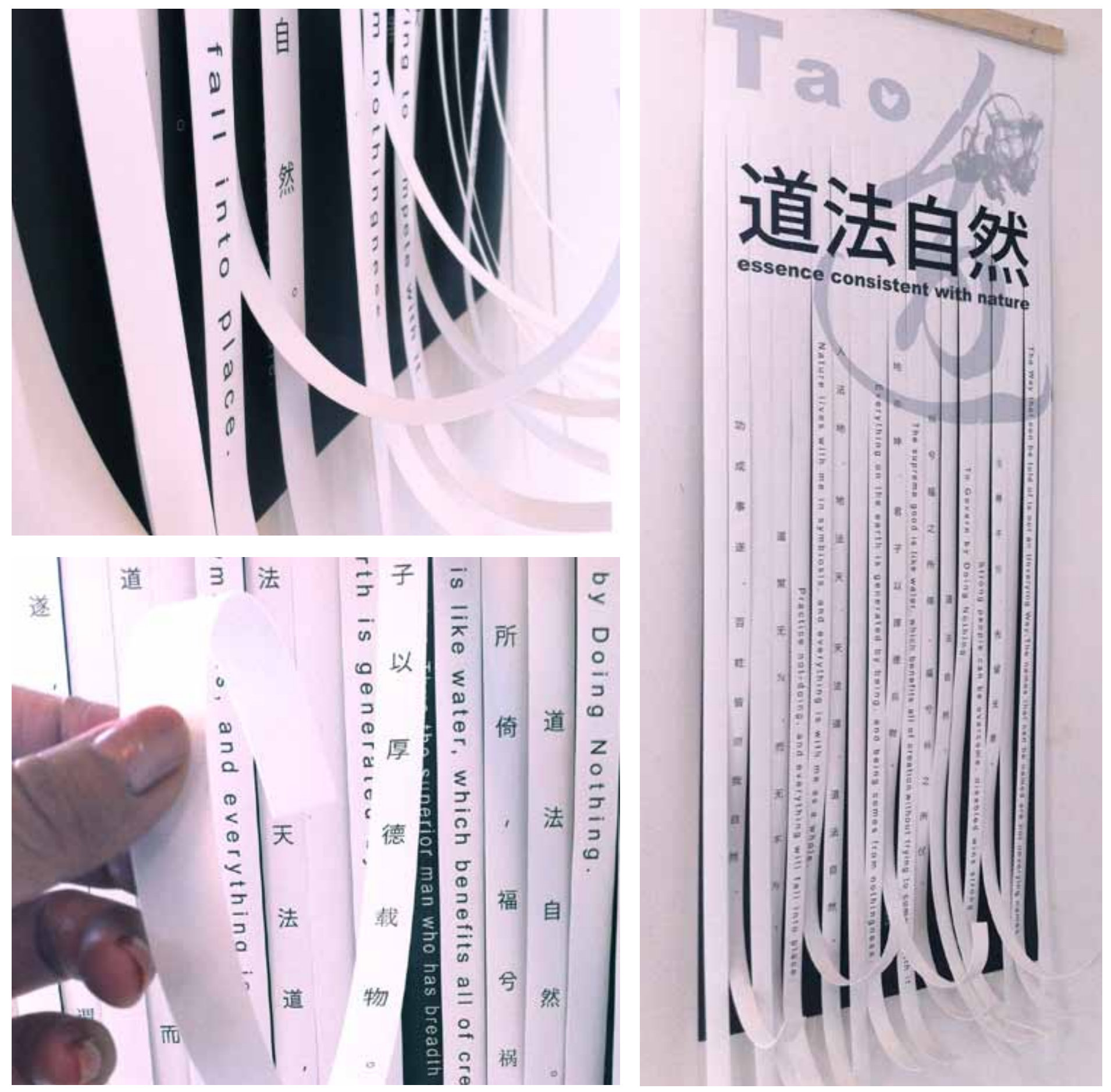

Essence Consistent with Nature, Bilingual Interactive Poster, 11 inches $x 22$ inches, 2012 

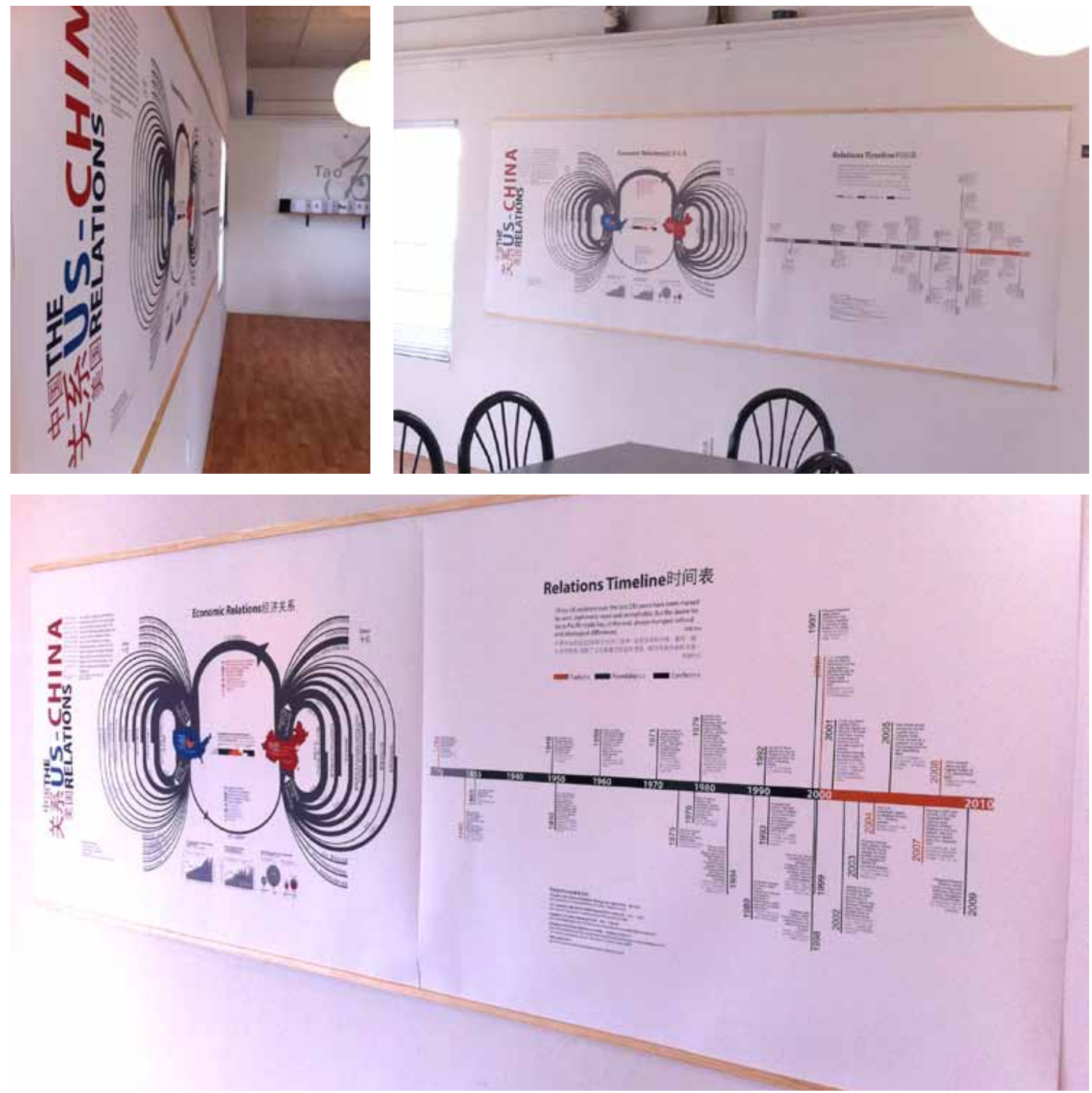

US-China Relations, Bilingual Information Graphics, 142 inches x 44 inches, 2012 

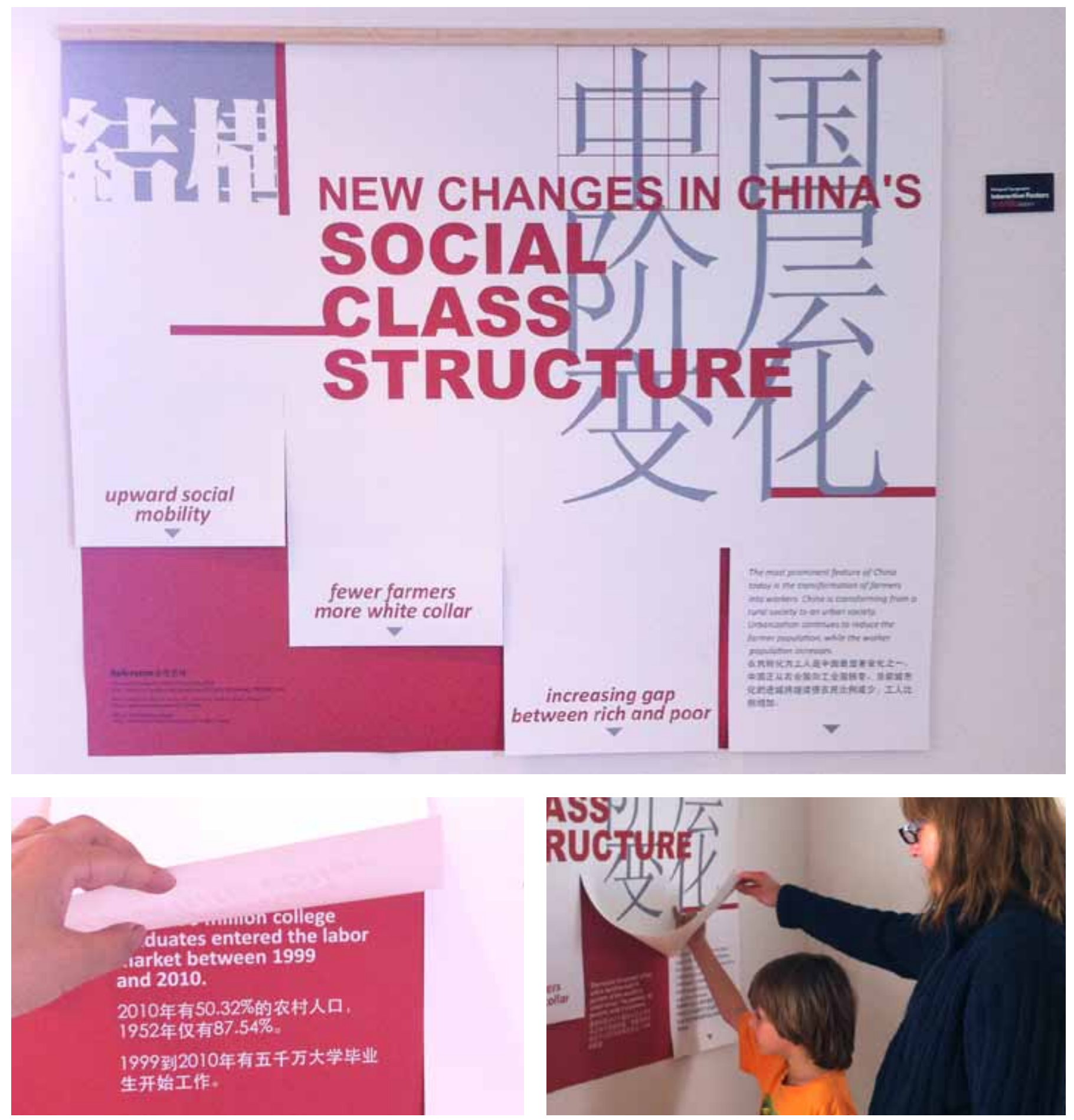

New Changes in China's Social Class Structure, Bilingual Interactive Poster, 58 inches $\times 44$ inches, 2012 


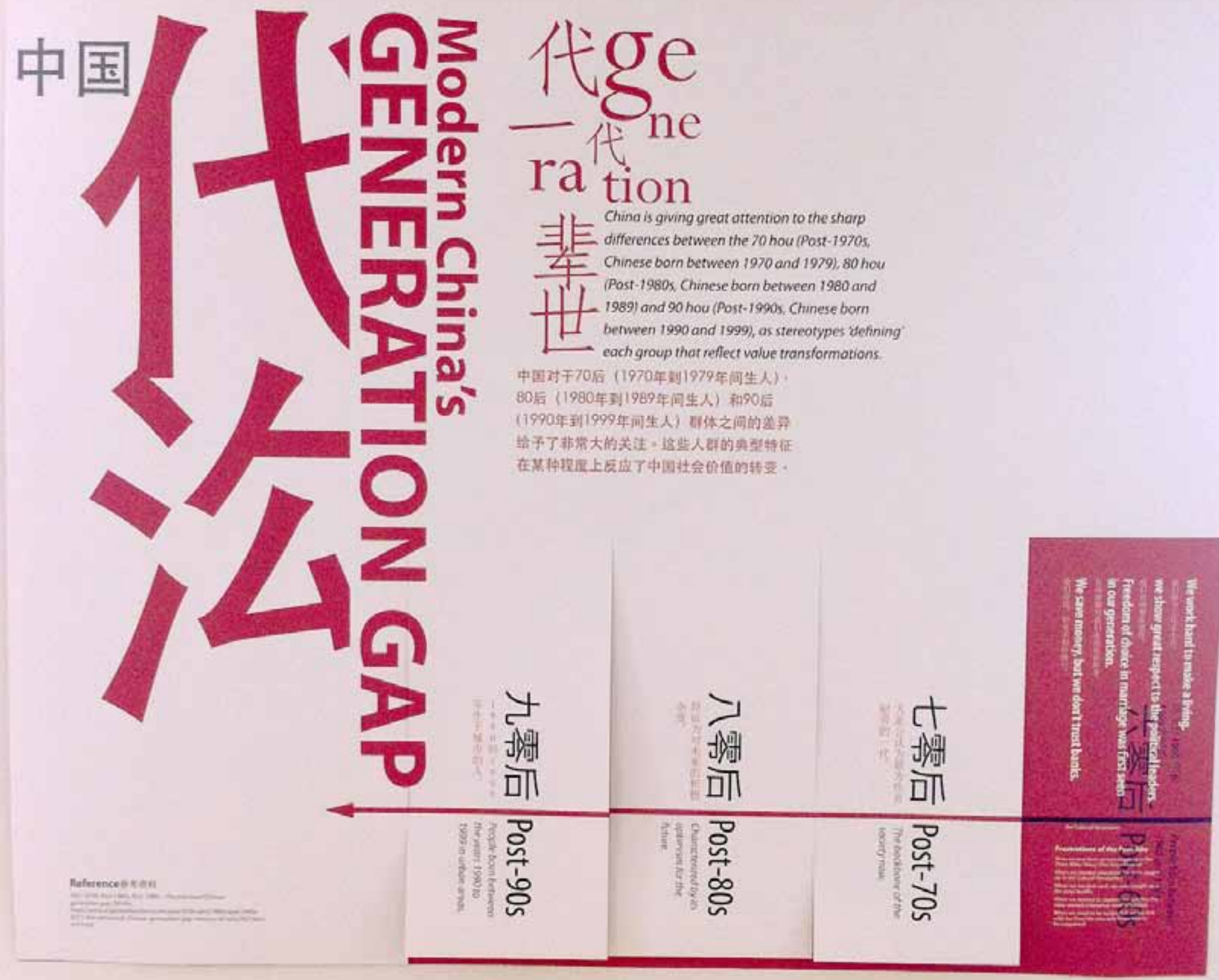

Modern China's Generation Gap, Bilingual Interactive Poster, 58 inches x 44 inches, 2012 

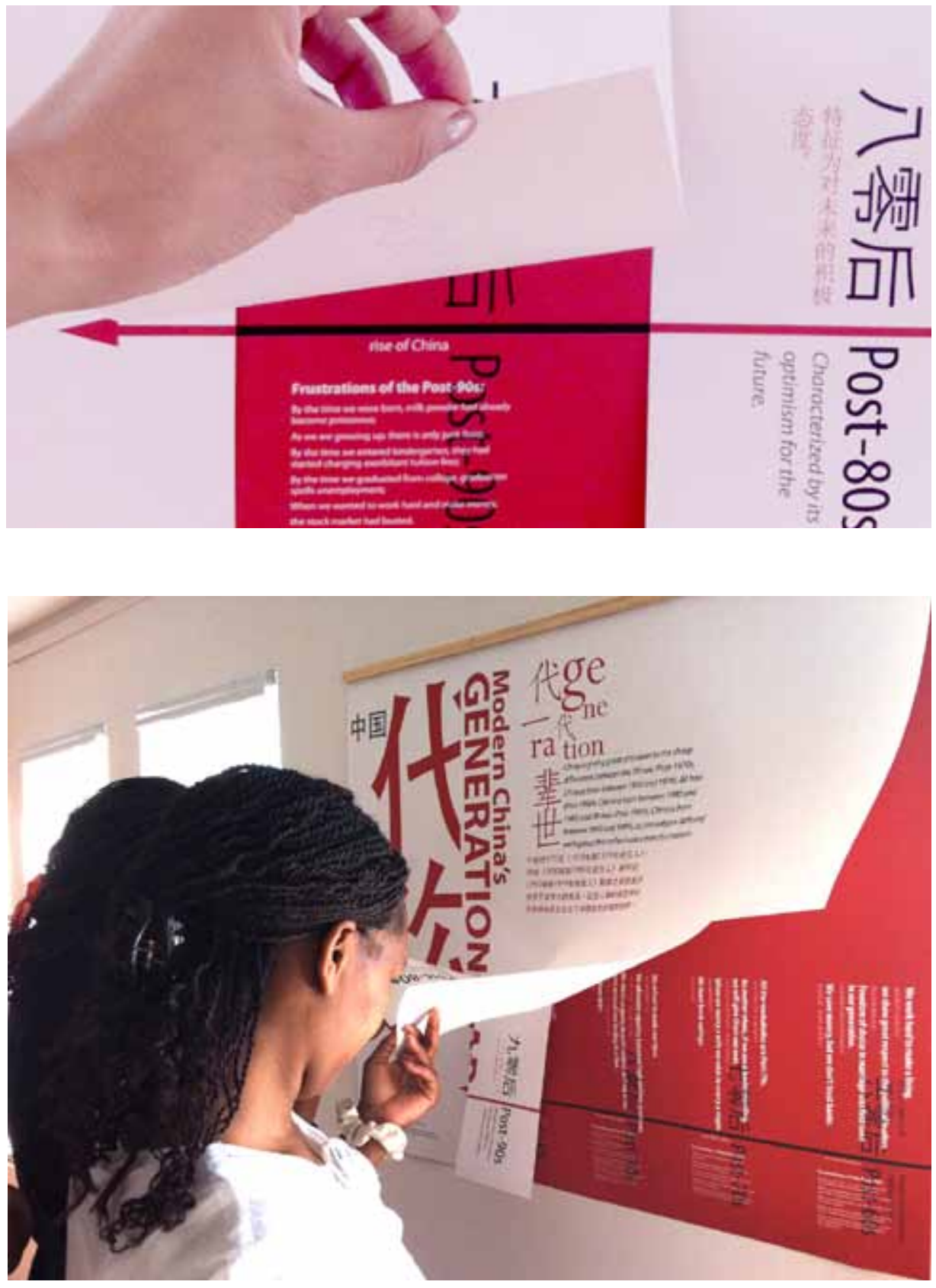

Modern China's Generation Gap, Bilingual Interactive Poster, 58 inches x 44 inches, 2012 


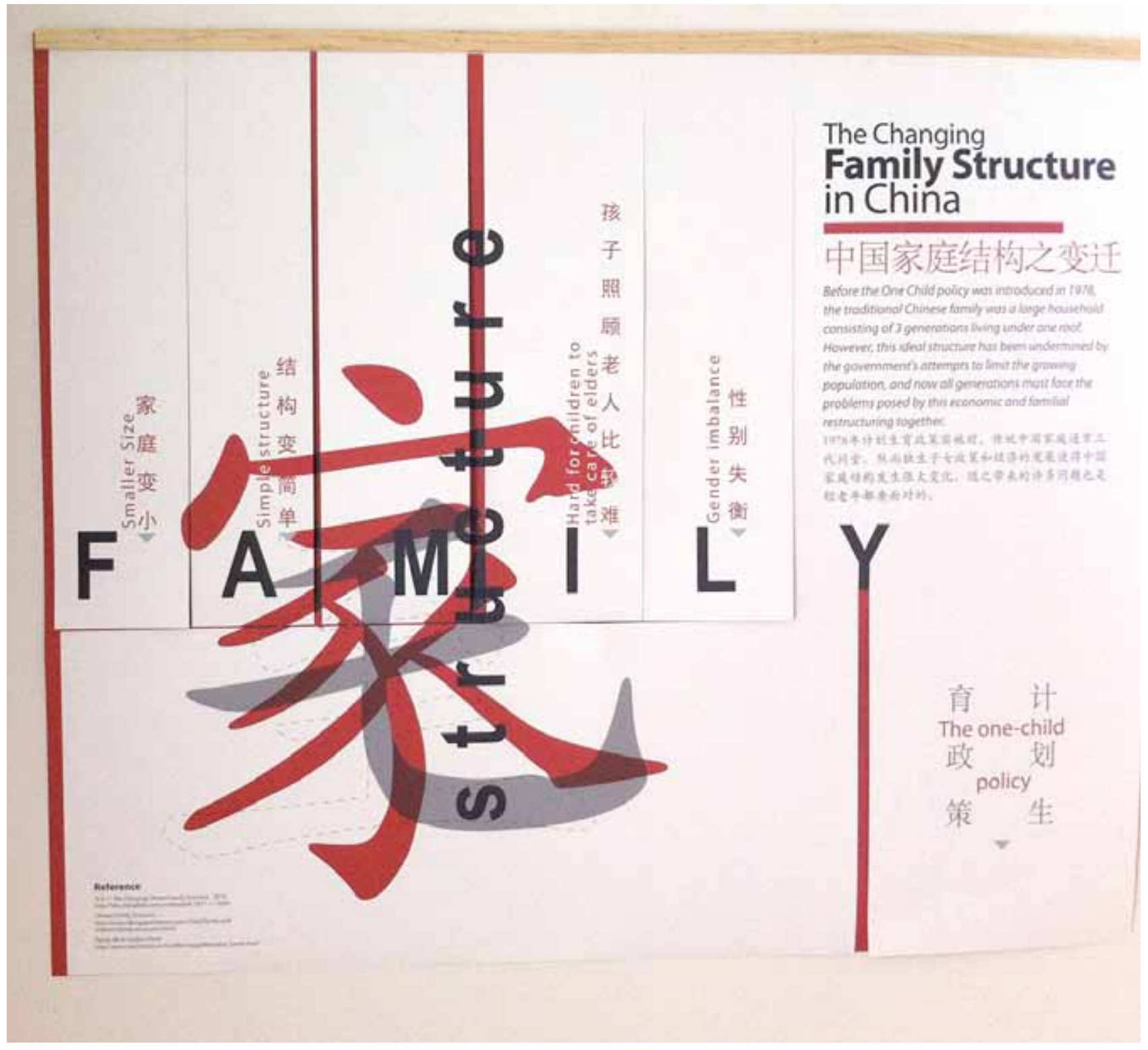

The Changing Family Structure, Bilingual Interactive Poster, 58 inches $\times 44$ inches, 2012 


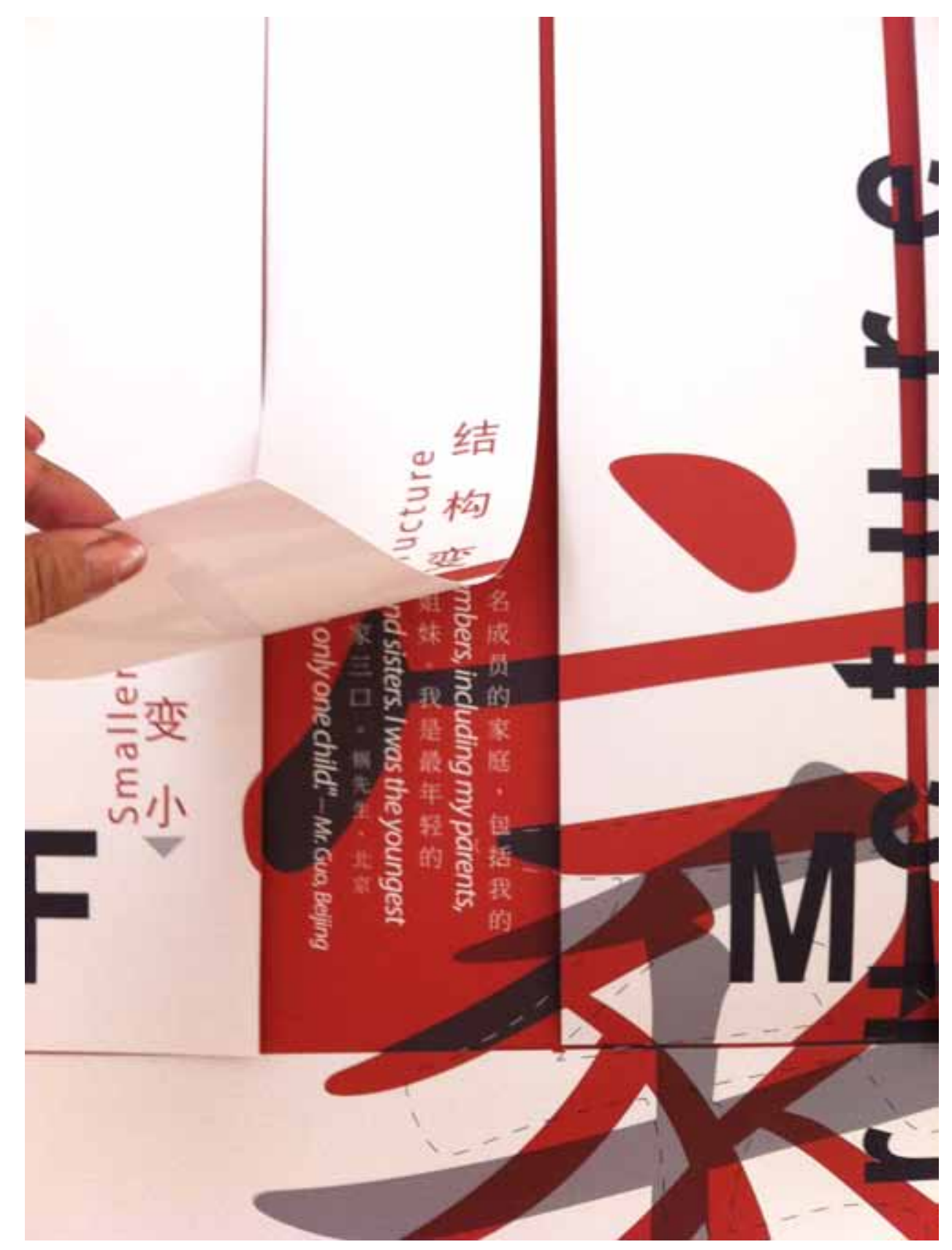

The Changing Family Structure, Bilingual Interactive Poster, 58 inches $\times 44$ inches, 2012 

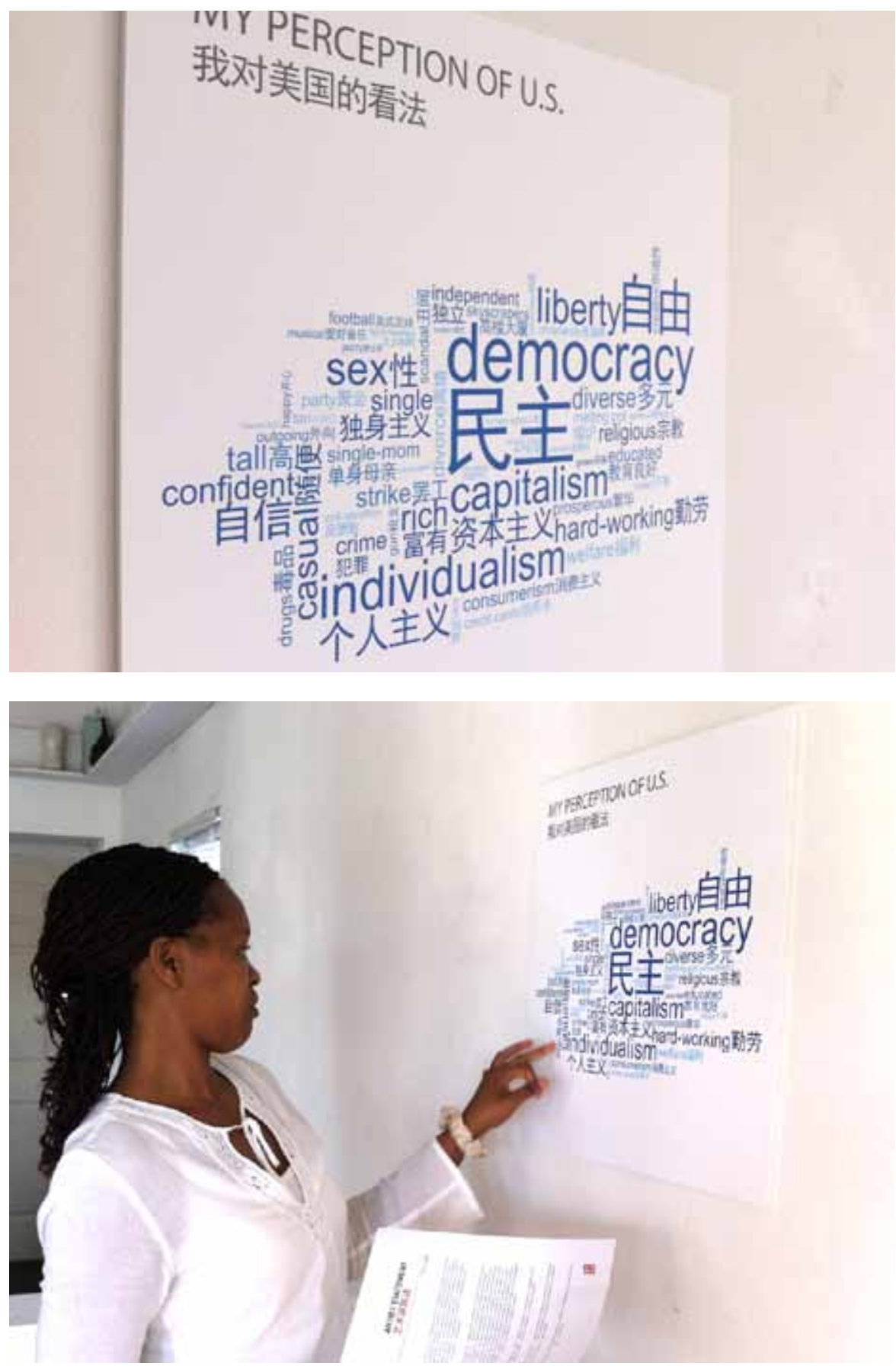

My Perception of U.S., Bilingual Information Graphics, 20 inches $x 20$ inches, 2012 


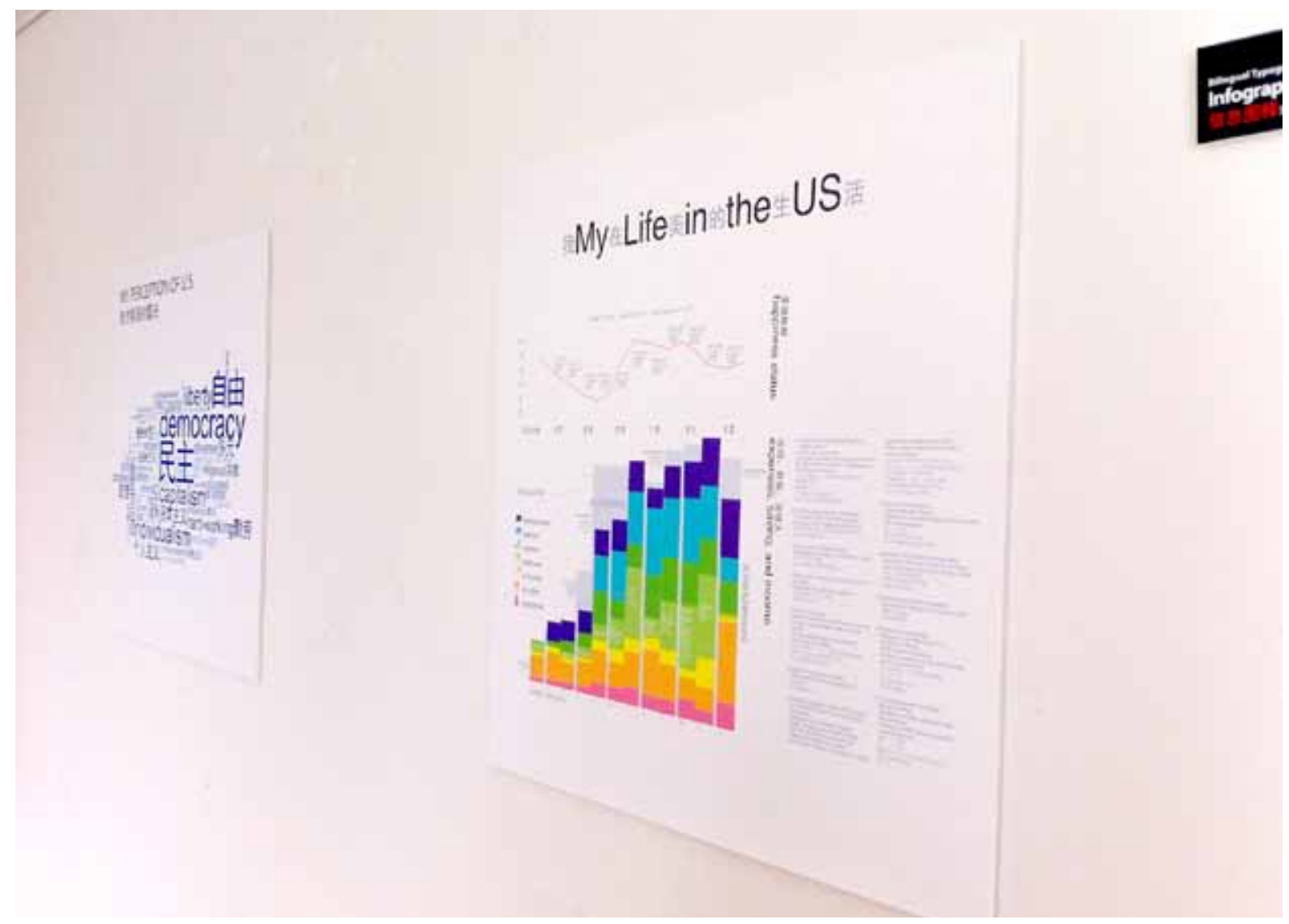

Left: My Perception of U.S., Bilingual Information Graphics, 20 inches $x 20$ inches, 2012

Right: My Life in the US, Bilingual Information Graphics, 20 inches x 20 inches, 2012 

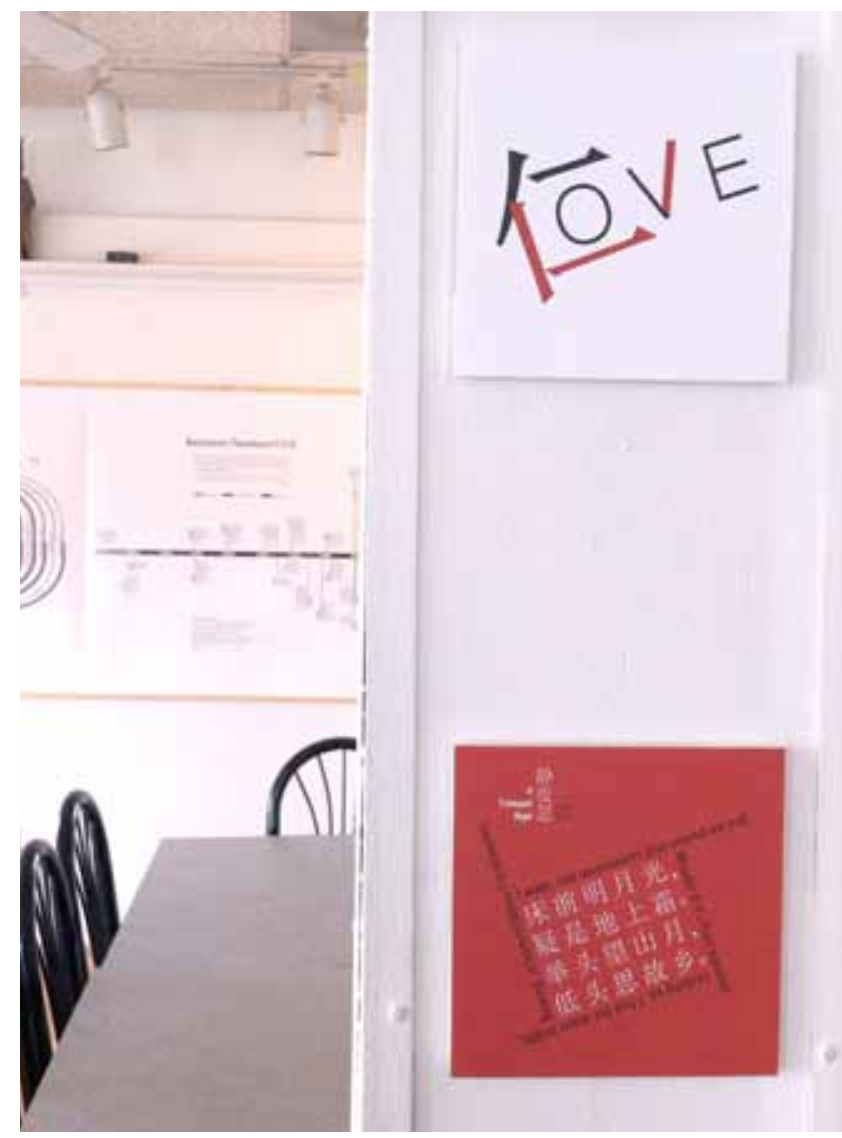

Top: Love, Illustration, 6 inches $x 6$ inches, 2012 Bottom: Peom 1, Illustration, 6 inches $\times 6$ inches, 2012
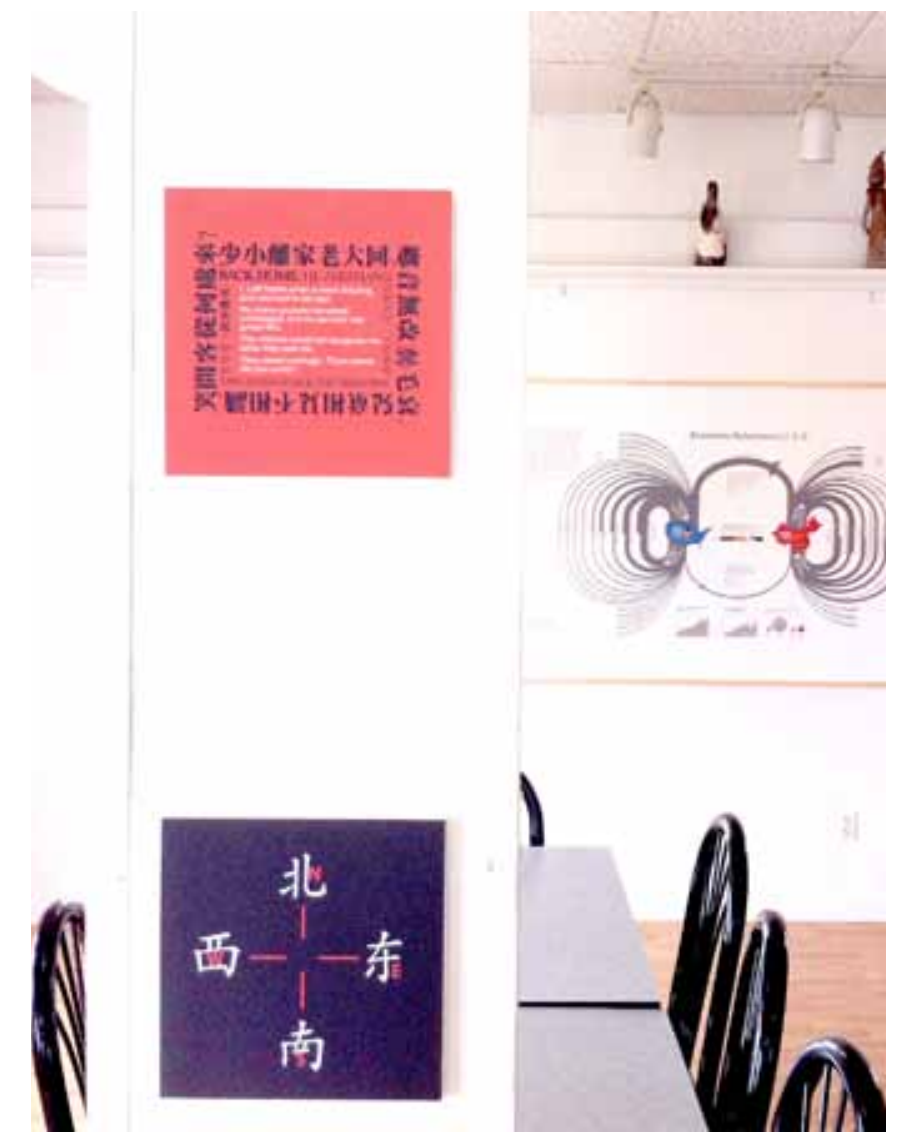

Top: Peom 2, Illustration, 6 inches $\times 6$ inches, 2012 Bottom: East, West, South, and North, Illustration, , 6 inches $\times 6$ inches, 2012

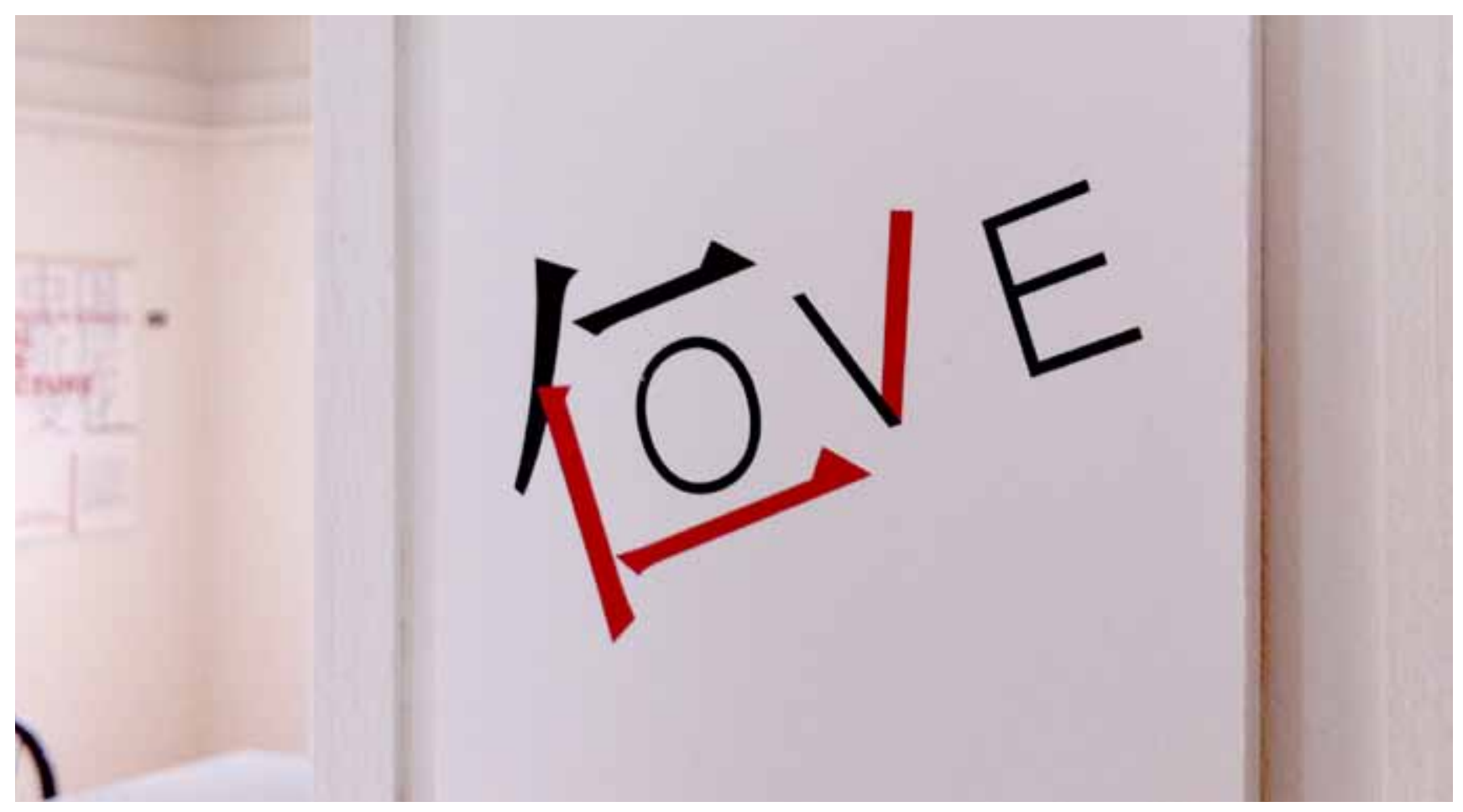

Love, Illustration , 6 inches $\times 6$ inches, 2012 


\section{展览作品名录 \\ List of Works Included in the Thesis Exhibit}

Illustration/Book:

Ways of Tao, Bilingual Accordion Book, 6.5 inches x 6.5 inches, 18 panels, 2011

Peom 1, Illustration, 6 inches $\times 6$ inches, 2012

Peom 2, Illustration, 6 inches $x 6$ inches, 2012

Love, Illustration, 6 inches $\times 6$ inches, 2012

East, West, South, and North, Illustration, 6 inches $\times 6$ inches, 2012

Letter, Illustration, 6 inches $\times 6$ inches, 2012

West Virginia, Illustration, 6 inches $\times 6$ inches, 2012

Interactive Poster:

New Changes in China's Social Class Structure, Bilingual Interactive Poster, 58 inches x 44 inches, 2012

Modern China's Generation Gap, Bilingual Interactive Poster, 58 inches x 44 inches, 2012

The Changing Family Structure, Bilingual Interactive Poster, 58 inches x 44 inches, 2012

Essence Consistent with Nature, Bilingual Interactive Poster, 11 inches X 22 inches, 2012

Information Graphics:

US-China Relations, Bilingual Information Graphics, 142 inches x 44 inches, 2012

My Perception of U.S., Bilingual Information Graphics, 20 inches $\times 20$ inches, 2012

My Life in the US, Bilingual Information Graphics, 20 inches x 20 inches, 2012 


\section{References参考文献}

Ellen Lupton, Thinking with Type: A Critical Guide for Designers, Writers, Editors, \& Students, Princeton Architectural Press, New York, 2004.

Marice Sy, Typographic Art: Xu Bing, Provisions, MAY 26, 2011, http://provisionslibrary. $\mathrm{com} / \mathrm{p}=8817$

Keith Tam, Typographic bilingualism: a framework for the coexistence of Chinese \& English texts, http://luc.devroye.org/fonts-39913.html, 2007.

Yao Wang, Chinese and English Typography in Graphic Design平面设计中英文字体的演变, Art and Design, p134, 2011

Liu Yangxi, A Comparative Research of Chinese-English Typefaces中英文字体比较研究, Art and Design, P74-75, 2011

Ben Wittne, Arabesque: Graphic Design From the Arab World and Persia, Die Gestalten Verlag; Mul edition, 2008

Wenping Yao, Comparison between Chinese and English Typography中英文匹配视觉研究， Science Information, p757-758, 2012

Hermann Zapf, Manuale Typographicum, The MIT Press, 1970.

Rules for Printed Text, http://www.cnpp86.com/bbs/dispbbs.asp?boardID=2\&ID=926\&page=1 Design2context, Multilingual Typography, http://multilingual-typography.zhdk.ch 